\title{
Income Dynamics and the Life Cycle
}

\section{John Rigg \\ Tom Sefton}

\begin{tabular}{|c|c|}
\hline \multicolumn{2}{|c|}{ Contents } \\
\hline 1. & Introduction. \\
\hline 2. & Data and Definitions.... \\
\hline 2.1 & Data ............................. \\
\hline 2.2 & Definition of income trajectories. \\
\hline 3. & Income Trajectories over the Life Cycle.. \\
\hline 3.1 & Definition of life stages... \\
\hline 3.2 & Income trajectories and life stages......... \\
\hline 3.3 & Income trajectories and other characteristics . \\
\hline 3.4 & How important are initial life stages in understanding income trajectories........ 16 \\
\hline 4. & 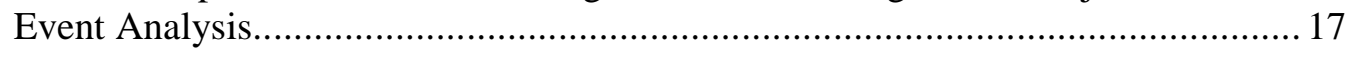 \\
\hline 4.1 & 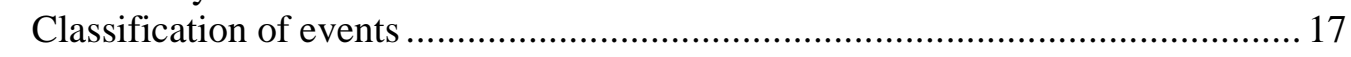 \\
\hline 4.2 & The importance of events for income trajectories ..... \\
\hline 5. & 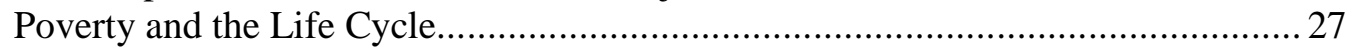 \\
\hline 6. & Overall Importance of the Life Cycle. \\
\hline 7. & 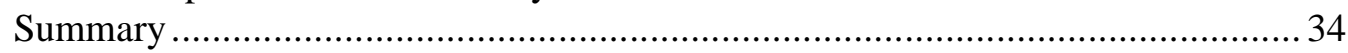 \\
\hline
\end{tabular}

CASEpaper 81

February 2004
Centre for Analysis of Social Exclusion

London School of Economics

Houghton Street

London WC2A $2 \mathrm{AE}$

CASE enquiries - tel: +44 (20) 79556679 


\section{Centre for Analysis of Social Exclusion}

The ESRC Research Centre for Analysis of Social Exclusion (CASE) was established in October 1997 with funding from the Economic and Social Research Council. It is located within the Suntory and Toyota International Centres for Economics and Related Disciplines (STICERD) at the London School of Economics and Political Science, and benefits from support from STICERD. It is directed by Howard Glennerster, John Hills, Kathleen Kiernan, Julian Le Grand, Anne Power and Carol Propper.

Our Discussion Paper series is available free of charge. We also produce summaries of our research in CASEbriefs, and reports from various conferences and activities in CASEreports. To subscribe to the CASEpaper series, or for further information on the work of the Centre and our seminar series, please contact the Centre Administrator, Jane Dickson, on:

$\begin{array}{ll}\text { Telephone: } & \text { UK+207955 6679 } \\ \text { Fax: } & \text { UK+20 79556951 } \\ \text { Email: } & \text { j.dickson@lse.ac.uk } \\ \text { Web site: } & \text { http://sticerd.lse.ac.uk/case }\end{array}$

(C) John Rigg

Tom Sefton

All rights reserved. Short sections of text, not to exceed two paragraphs, may be quoted without explicit permission provided that full credit, including (C notice, is given to the source. 


\section{Editorial Note}

John Rigg is a Research Officer in the ESRC Research Centre for Analysis of Social Exclusion (CASE) at the London School of Economics. Tom Sefton is a Research Fellow in CASE.

\section{Acknowledgements}

The authors are grateful to the Economic and Social Research Council for funding this work. They would also like to thank John Hills for providing advice and guidance throughout the project and Abigail McKnight for editing this CASE paper.

\section{Abstract}

This paper argues that our understanding of income and poverty dynamics benefits from taking a life cycle perspective. A person's age and family circumstances - the factors that shape their life cycle - affect the likelihood of experiencing key life events, such as partnership formation, having children, or retirement; this in turn affects their probability of experiencing rising, falling, or other income trajectories. Using ten waves of the British Household Panel Survey, we analyse the income trajectories of people at different stages in their lives in order to build a picture of income dynamics over the whole life cycle. We find that particular life events are closely associated with either rising or falling trajectories, but that there is considerable heterogeneity in income trajectories following these different events. Typically, individuals experiencing one of these life events are around twice as likely to experience a particular income trajectory, but most individuals will not follow the trajectory most commonly associated with that life event. This work improves our understanding of the financial impact of different life events and provides an indication of how effectively the welfare state cushions people against the potentially adverse impact of certain events.

JEL numbers: D31, I32, J18

Key words: income dynamics, life cycle, poverty 


\section{Introduction}

Writing at the beginning of the twentieth century, Rowntree was one of the first to highlight the alternating periods of want and plenty typically associated with the different stages in people's lives:

"The life of a labourer is marked by five alternating periods of want and comparative plenty. During early childhood ... he will probably be in poverty ... there then follows a period during which he is earning money and living under his parents' roof ... This period of prosperity may continue after marriage until he has two or three children when poverty will overtake him. This period of poverty will last perhaps for ten years until the first child is fourteen years old and begins to earn wages ... the man enjoys another period of prosperity only to sink back again into poverty when his children have married and left him, and he himself is too old to work." (Rowntree, 1902, quoted in Glennerster, 1995, p. 10)

This paper provides a contemporary, empirical perspective on Rowntree's insights on alternating times of want and plenty. We investigate the income dynamics associated with different life stages, defined with respect to a person's family circumstances, as well as age. We examine, for example, whether a young adult in a couple without children is more likely than average to experience a rising or falling income.

A key element in the importance of the life cycle is that each life stage in part determines the probability of experiencing certain life events, which in turn are likely to have consequences for income. A young adult living in a childless couple, for example, faces a higher than average probability of having children, which may be associated with a fall in living standards. Thus, in addition to assessing the probability of following particular income trajectories at different life stages, we also directly examine the association between life cycle events and different income trajectories: how do events, such as partnership formation and dissolution, having children, retirement and the death of a spouse, affect the probability of moving up or down the income distribution?

The most up-to-date picture of incomes over the life course is provided by Falkingham and Hills (1995), which is based on a dynamic micro-simulation model using cross-sectional data from the mid 1980s. They model household incomes over the life-times of a 'synthetic' population. Important 'events' in the lives of people, such as their employment history and household formation or dissolution, are simulated in order to create hypothetical life-histories, under the 
assumption that everyone is born into and lives their entire lives in a fixed economic, social, and policy environment.

They find that the alternating periods of want and comparative plenty are no longer as clearly evident a century after Rowntree first described them. Their model suggests that, on average, there is a sharp rise in incomes in early adulthood, followed by a period of relatively flat incomes (not a period of want), a small peak in middle age, and a fall on retirement. Our own analysis using data from the British Household Panel Survey shows a similar pattern over the life cycle for changes in relative incomes (see Figure 1).

The profile of incomes over the life cycle has not only changed but has probably become more variable than the one described by Rowntree. As Glennerster (1995) points out, a wide range of factors have impacted on the modern life cycle including longer length of schooling, increasing pay differentials by skill, falling labour market participation by older men, more fragile marriages, more complex patterns of partnership, lower fertility rates, increased employment opportunities for women and longer life expectancy. Many of these will have contributed to a greater heterogeneity in individuals' experiences. Falkingham and Hills (1995) find considerable variation between individuals and subgroups: between ever and never married men, for example, and between couples with and without children. The conceptual relevance of the life cycle - that different stages in life are systematically associated with changing fortunes needs, therefore, to be re-examined.

The analytical approached used in Falkingham and Hills (1995) is the most sophisticated means of examining this issue in the absence of panel data. However, their model is built on a series of assumptions and a probabilistic distribution of life events, the combined effect of which is impossible to validate because the construct is an artificial one - no one, in practice will ever live their entire lives in an unchanging environment. In this paper, we take advantage of recently available data from ten years of the British Household Panel Survey on 'real' people, rather than simulated life histories. This overcomes many of the limitations inherent in dynamic micro-simulation, in particular the problems of trying to model the complex and inter-related events that help to determine people's incomes over time. A major drawback is that we still only have data on ten years in people's lives. Thus, we make comparisons between people at different stages in their lives in order to build up a picture of income dynamics over the whole life cycle. 
Figure 1: Changes in Incomes over the Life Cycle ${ }^{1}$

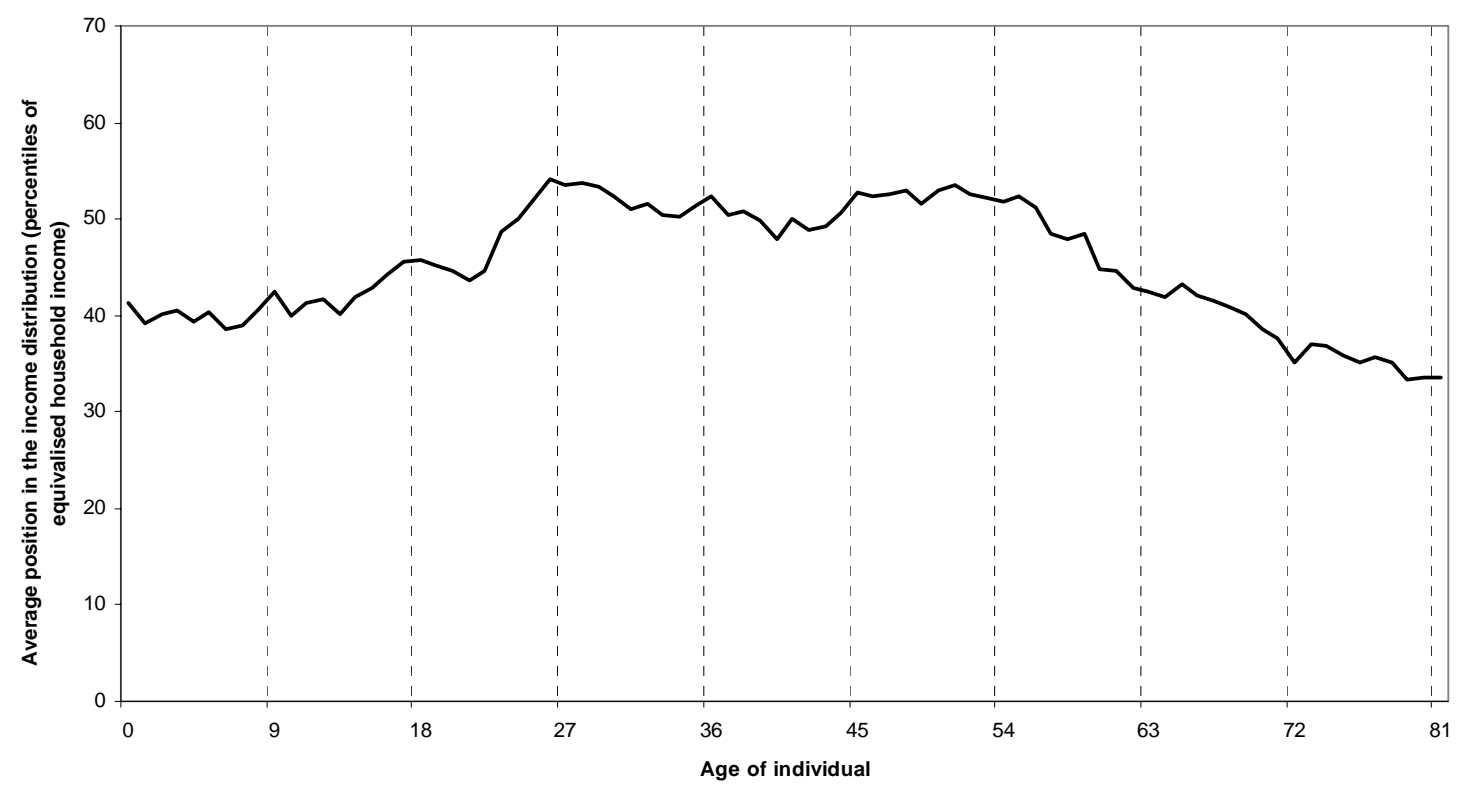

Note:

1. Based on the first ten waves of the BHPS. We define ten age cohorts - sub-samples of people who in wave one are aged 0-4, 7-11, 16-20, etc. (Five year bands are used to generate large enough sub-samples.) For each age cohort, we calculate their average position in the income distribution over each of the ten waves of the BHPS. To avoid discontinuities in the graph, data for the tenth year of the first age cohort and the first year of the second age cohort is used to adjust the results for the second age cohort, and so on for successive age cohorts. (In practice, these adjustments are relatively small.)

Previous research using the British Household Panel Survey (BHPS) has examined the prevalence of persistent poverty among different demographic groups and also the association between different life events and entries into or exits from poverty (Jarvis and Jenkins, 1997; Jenkins and Rigg, 2001). A smaller strand of research has looked at changes in incomes before and up to three years after the onset of specific events, such as partnership breakdown (Jarvis and Jenkins, 1999), retirement (Bardasi, Jenkins and Rigg, 2002), widowhood (Zaidi, 2001) and disability (Jenkins and Rigg, 2003). The results of these studies are discussed later in the light of our own findings.

This paper extends this existing body of work in a number of important respects. Building on the approach of Gardiner and Hills (1999), we distinguish six types of income trajectory: flat, flat with blips, rising, falling, fluctuating and other. We consider incomes across the entire income distribution, not just those in the lower part of the distribution - the emphasis of most existing research. Moreover, we analyse income changes over ten years, rather than wave-onwave changes in the case of most research, or four waves of the BHPS in the 
case of Gardiner and Hills (1999) and some other studies (e.g. Jenkins and Rigg, 2003). This enables us to assess the importance of events, the impact of which may not be fully realised when looking only at concurrent or relatively shortterm changes in income. The impact of having children, for example, will have repercussions on household income many years after the birth of a child if, for example, the parents gradually adjusts their labour market participation in line with changes in their parenting responsibilities.

This work has several potential implications for policy. Firstly, it may help to inform a preventative approach to tackling poverty by identifying groups at particular stages in their life cycle who are most likely to experience problematic trajectories over an extended period of time. Secondly, it improves our understanding of the financial impact of different life events and provides an initial indication of how effectively the welfare state cushions people against the potentially adverse impact on income of, for example, the onset of disability or retirement.

The outline of the paper is as follows. Section 2 provides details of the data and definitions, including our six-fold classification of income trajectories. Sections 3 to 6 discuss the results. Section 3 examines the income trajectories experienced by individuals at different life stages, whilst Section 4 examines the association between income trajectories and different life events. In Section 5, we look at poverty and the life cycle, focusing on income trajectories that involve movements into and out of low income. Section 6 considers how well life stages and events explain the overall variation in income trajectories and assesses their relative importance compared with the impact of labour market factors. The final section summarises our main findings.

\section{Data and Definitions}

\subsection{Data}

This analysis uses data from the first ten waves of the British Household Panel Survey (BHPS), covering the period 1991 to 2000. ${ }^{1}$ The first wave of the BHPS was designed to be a nationally representative sample of the population of Great Britain and original sample members (and their co-residents) are interviewed at approximately one-year intervals. The analysis is based on a balanced panel of 5316 individuals who lived in complete respondent households for all ten

The derived income variables for wave eleven were not yet available at the time of writing. 
waves. ${ }^{2}$ This represents approximately one-third of all individuals in the wave one cross-section. To account for non-response in the initial wave of interviews and for differential attrition in subsequent waves, we use the relevant BHPS sample weights where appropriate.

The measure of income we use is current net household equivalised income (before housing costs). This includes all cash income from household members at the time of the interview and is adjusted for household needs using the McClements scale. The income data is created by the Institute for Social and Economic Research at the University of Essex and deposited with the UK Data Archive (for documentation and codebook, see Bardasi, Jenkins, and Rigg, 2001).

On the basis of this income measure, individuals in wave one are divided into percentile groups. Following Gardiner and Hills (1999), the income cut-offs denoting the boundaries of the wave one percentile groups are adjusted in line with the growth in average incomes between successive waves. We refer to these as "quasi-percentiles".

\subsection{Definition of income trajectories}

Individuals are classified into one of six broad types of income trajectory. Our starting point was the five trajectory types identified by Gardiner and Hills (1999): flat, flat with blips, rising, falling, and other. ${ }^{4} \mathrm{We}$ examined the possibility of new trajectory types that might be observable over a longer time frame, including U-shaped, inverted U-shaped and fluctuating trajectories. There were insufficient cases that fitted a U-shaped or inverted U-shaped

2 Complete responses are needed from all household members in order to estimate net household income, the key variable in our analysis.

If the overall shape of the distribution remained unchanged throughout the period, there would be exactly one hundredth of the sample in each quasi-percentile in all waves. But if, for example, those on low incomes experienced above average income growth, then the proportion of individuals in the bottom groups would fall over time. This seems preferable to taking actual percentile groups in each wave, though in practice it makes little difference over this period.

As described below, the definitions of the different income trajectories adopted by Gardiner and Hills (1999) were adapted slightly to reflect the availability of more waves of data. For example, the classification of rising and falling trajectories used in Gardiner and Hills did not allow for any movement in the opposite direction, however small. Imposing an identical rule over ten waves, would (unrealistically) result in very few cases following either of these trajectories. We therefore relaxed the criteria to permit movements in the opposite direction, provided the overall trend was clearly rising or falling over the period as a whole. 
pattern for these to be analysed as distinct groups. These trajectories were therefore included in the "other" category, along with cases that did not readily fall into any of the other five trajectory types. By contrast, the fluctuating category provided a good description for a non-trivial number of cases and was retained as a separate category. The fluctuating category is also of interest since it is in keeping with income profiles often associated with self-employment as well as phenomena, such as, the 'low pay-no pay' cycle (Stewart, 1999) which may be of particular relevance for income movements in the lower part of the distribution.

The precise formulation of each trajectory type was based on an iterative process, using visual inspection of income patterns to determine rules regarding, for example, the degree of 'acceptable' variation around the mean of a 'flat' trajectory. We showed a small number of people graphical representations of the income trajectories of 150 random individuals from our BHPS sample and asked each person to classify these individuals into one of the six income trajectories. By focusing on the minority of cases that people classified differently - the borderline cases - we were able to determine appropriate boundaries between different trajectory types. In the example above, this process suggested that an individual's position in the income distribution could vary within a band of plus or minus 15 quasi-percentiles and still be regarded as flat. ${ }^{5}$ In the case of rising and falling trajectories, more variation around the trend was acceptable for steeper trends. Different ways of coding these definitions were formulated and tested to ensure there was a close match with people's visual interpretation of these income trajectories.

The six trajectory types are defined below and illustrative examples of each are provided in Figure 2:

1. Flat: Relatively stable position in the income distribution over all ten waves: all observations within a band of plus or minus fifteen quasipercentiles from the mean.

2. Flat with blips: As above, but allowing up to two one-wave blips or one two-wave blip ${ }^{6}$ in either direction over the ten waves. A 'blip' is

$5 \quad$ By coincidence, this matches the rule applied by Gardiner and Hills (1999) in the bulk of their analysis. The reason they chose a 15 percentile criterion for movement is that this is roughly equivalent to the rule that a trajectory is 'flat' if it crosses no more than one decile group boundary. 15 percentiles is the average movement that would still qualify as 'flat' under this rule.

6 Two-year blips are not treated as such if they occur in waves 1 and or 9 and 10, since it is not possible to tell whether these represent a genuine blip or the beginning of a rising or falling income trajectory. In these cases, the income trajectory is classified in the "other" category. 
defined as a deviation of more than 15 quasi-percentiles from the mean. ${ }^{78}$

3. Rising: A significant move up the income distribution, equivalent to at least fifteen quasi-percentiles over the ten waves. Some downward movement is permitted provided the overall trend is positive and significant. ${ }^{9}$

4. Falling: A significant move down the income distribution, equivalent to at least fifteen quasi-percentiles over ten waves, applying the same criteria used to define rising trajectories.

5. Fluctuating: at least three substantive movements up and down the income distribution - up/ down/ up or down/ up/ down - over the ten year period. ${ }^{10}$

6. Other: All other income patterns not classified above.

The mean is computed using eight of the ten observations excluding two outliers (i.e. those furthest away from the mean for all observations).

Identification of blips is designed to capture short-term fluctuations in income, although blips may also arise from measurement error.

Significance is determined by regressing the income observations against a linear time trend using ordinary least squares estimation. A positive and significant coefficient on the linear time trend (at the ten per cent level or higher) is interpreted as evidence of a significant rise in income. To ensure that the trend is not being 'artificially' generated by outliers, we test that the coefficient is still significant without two outliers. (The first outlier is the observation furthest away from the trend line for all observations and the second outlier is the observation furthest away from the trend line for nine observations excluding the first outlier.) versa) has to be at least 22.5 quasi percentiles in each case. 
Figure 2: Types of Income Trajectory

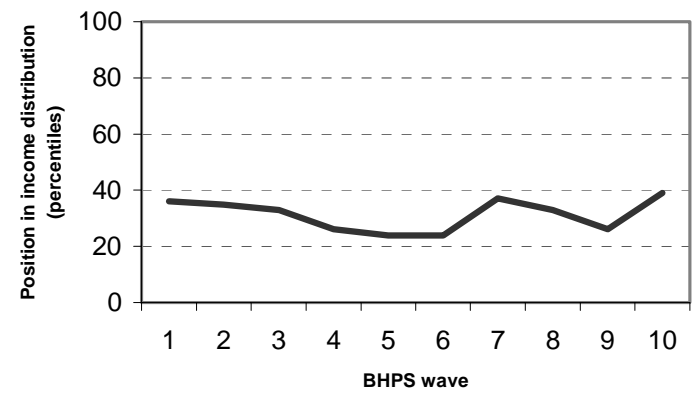

Flat trajectory

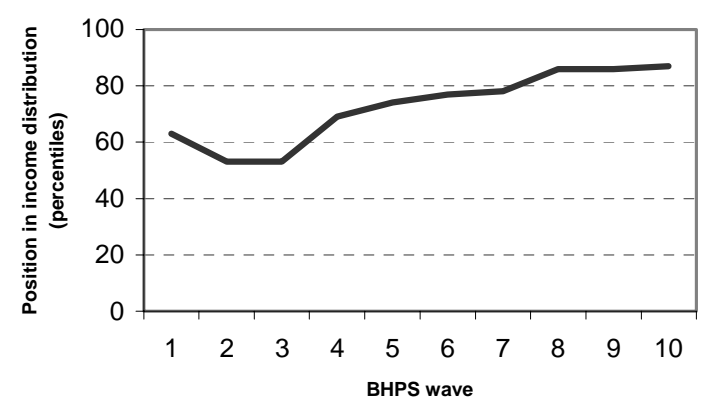

Rising trajectory

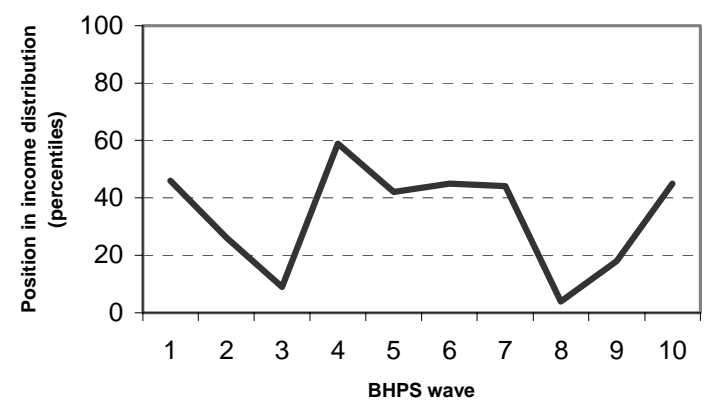

Fluctuating trajectory

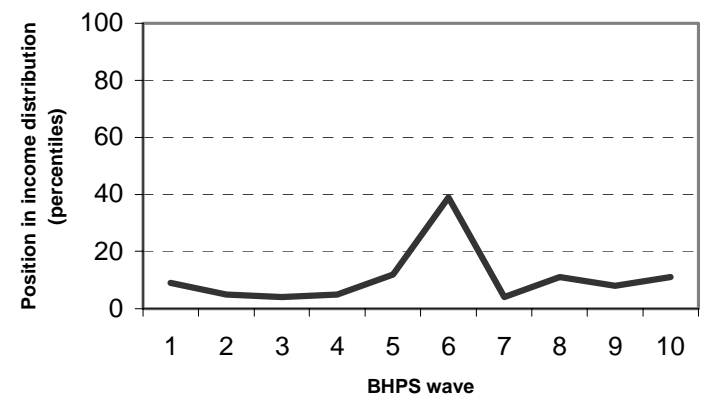

Blipping trajectory

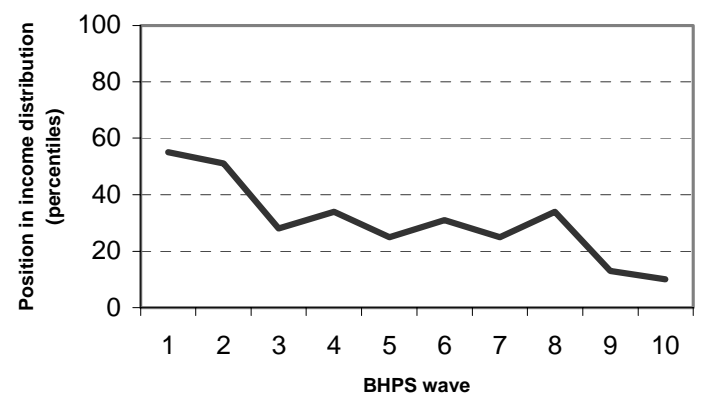

Falling trajectory

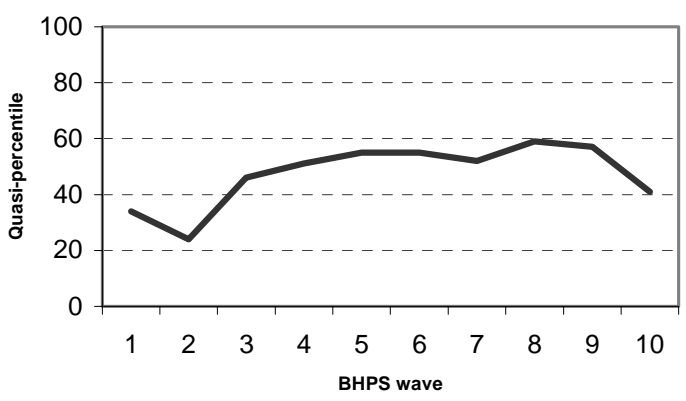

Other trajectory 
The breakdown of income trajectories is shown in Table 1. Over the ten year period, around half of all individuals follow a broadly flat income trajectory, split approximately equally between those with a 'flat' and those with a 'flat with blip' trajectory. A quarter of individuals have either rising or falling trajectories and one eighth have fluctuating trajectories. The remainder of cases - around an eighth of the sample - do not fit into any of these categories.

Table 1: Income Trajectories by Type

\begin{tabular}{|c|c|c|c|}
\hline Trajectory types & $\begin{array}{l}\text { Ten waves } \\
\text { BHPS data } \\
\text { (\% of cases) }\end{array}$ & $\begin{array}{c}\text { Ten waves } \\
\text { Random dataset }^{2} \\
(\% \text { of cases })\end{array}$ & $\begin{array}{c}\text { Four waves } \\
\text { BHPS data } \\
\text { (\% of cases) }\end{array}$ \\
\hline Flat & 24.3 & 0.0 & 45.6 \\
\hline Flat with blip(s) & 23.8 & 1.1 & 13.1 \\
\hline Rising & 12.6 & 4.1 & 11.3 \\
\hline Falling & 14.3 & 3.8 & 13.1 \\
\hline Fluctuating & 12.6 & 88.2 & \\
\hline Other & 12.5 & 2.8 & 17.0 \\
\hline
\end{tabular}

Source: Own analysis using BHPS.

Notes:

1. Waves 1-4 for individuals with non-missing income for waves 1-10.

2. Based on Monte Carlo analysis with 10,000 randomly generated observations. See footnote 11.

Even at random, a certain amount of cases will fall into one of the first five trajectory types (i.e. not the "other" category). In other words, some individuals may appear to be following a systematic income pattern, but this may be the product of random variations from one wave to the next. To assess the extent to which the distribution of trajectory types observed in our sample may be the product of systematic or random processes, we compared the observed distribution with one generated using a Monte Carlo experiment on a hypothetical dataset of ten thousand individuals, each with ten randomly generated income observations. ${ }^{11}$

For each of the 10,000 'individuals' in our hypothetical dataset, ten random numbers from 1 to 100 were generated to represent their position in the income distribution (in percentiles) for each of the ten waves. The pattern created by these random observations was classified into one of our six trajectory types using the same criteria as for the BHPS sample. This assumes that 'individuals' in the hypothetical data set are completely independent of one another, whereas individuals in the BHPS are clustered in households with a shared income (though not necessarily the same household in all waves). 
Results from the Monte Carlo experiment are also reported in Table 1. The probability of an individual following a flat or flat with blip trajectory at random is just one per cent, compared to around half of all individuals in our sample. Within the random dataset, only $3-4 \%$ of cases fall into each of the rising or falling categories, compared to $13-15 \%$ in the actual data set. These large discrepancies between the distribution of trajectory types in the actual and hypothetical datasets suggests that the vast majority of observed income patterns are not random. The one possible exception is the "fluctuating" category, which accounts for nearly $90 \%$ of the random trajectories. We cannot be certain, therefore, whether this is a distinct, meaningful trajectory type that appropriately describes the experience of some of the individuals in our sample or whether these individuals fall into this category at random. However, the fact that individuals with particular characteristics (e.g. the self-employed) are more likely to follow a fluctuating trajectory suggests that this type of trajectory is driven by systematic processes.

The distribution of trajectory types based on the first four waves of the BHPS is also shown in Table $1 .{ }^{12}$ As expected, the proportion of flat trajectories is substantially lower - around half - over ten waves than it is over four waves. Events that lead to significant changes in household income are more likely to be observed over an extended period. A more detailed analysis of individuals' income trajectories over four and ten waves shows that those who experience a given trajectory over four waves are more likely than average to experience the same trajectory over ten waves (see appendix Table A1). However, less than half of those who had flat trajectories over four waves continued to have flat trajectories over the full ten waves, whilst less than a quarter of those who experienced rising or falling trajectories over four waves continued on the same trajectory over ten waves. For the majority of those on a rising or falling trajectory over four waves, this trend appears as a 'blip' or 'other' trajectory when looked at over ten waves. Thus, our ten wave trajectories appear to be capturing longer-term trends in household income that cannot be predicted on the basis of their income trajectories over a shorter period.

\section{Income Trajectories over the Life Cycle}

We start by investigating the income trajectories associated with different stages in people's lives. Is the concept of the life cycle still meaningful in the sense

12 The four-wave trajectory typology is similar to that developed by Gardiner and Hills (1999). The main difference is that small falls (or rises) were allowed in otherwise rising (or falling) trajectories. 
that different life stages are associated with particular types of income trajectory? If so, how strong is the association between life stages and particular income trajectories and does this hold once other factors that may also affect individuals' income trajectories are controlled for?

\subsection{Definition of life stages}

We assign all individuals in our sample to one of the following ten (mutually exclusive) life stages, based on their characteristics in wave one:

$>$ Dependent child: aged under 16 (or aged 16-18 and in full-time education);

$>\quad$ Young, single adult: aged 35 or under;

$>\quad$ Young adult in childless couple: married or cohabiting and aged 35 or under;

$>$ Adult in couple with young children: with at least one child aged 5 or under; ${ }^{13}$

$>\quad$ Adult in couple with older children: all children aged over 5;

$>$ Single parent;

$>\quad$ Older adult in childless couple: married or cohabiting and aged over 35;

$>\quad$ Older single adult: aged over 35;

$>$ Pensioner in a pensioner couple: living in a household where either the household head or spouse is of pensionable age, ${ }^{14}$

$>\quad$ Single pensioner.

These life stages are not sequential. Indeed, there is likely to be considerable heterogeneity in the sequence of life stages followed by different individuals. Furthermore, most individuals will not experience all of these life stages, whilst some will experience certain life stages more than once over their lifetime.

In allocating individuals in our sample between the ten life stages according to their characteristics in wave one, we take no account of the duration to date nor the (expected) outstanding duration in that particular life stage. Some individuals will just have entered a particular life stage and may remain in it for some time, whilst others will be about to make the transition to another life stage, which will affect the types of income trajectory they might be expected to follow.

13 The distinction between adults in couples with younger and older children is designed to capture the possible impact of having pre-school children (primarily) through the effect on mothers' employment patterns.

14 Aged 60 or over for women and 65 and over for men. 
Nevertheless, the classification of life stages is useful in helping to identify broadly where people are in their life cycle. It is preferred to the traditional approach of looking at the life cycle purely in terms of age, because it is better at capturing the likelihood of experiencing important life cycle events, such as partnership formation and having children, which occur at different ages in different people's lives.

\subsection{Income trajectories and life stages}

The proportion of individuals experiencing each of the six income trajectories is shown in Table 2. The figures are broken down according to individuals' life stage in wave one. The evidence clearly shows that different life stages are associated with particular income trajectories. Children, young and single adults, single parents and adults in couples with older children are the most upwardly mobile. People at these stages in their lives are more likely than average to experience improvements in their financial circumstances. For example, $24 \%$ of single parents experience rising trajectories over the ten waves, compared to $13 \%$ of all individuals in our sample. The most downwardly mobile individuals are adults in childless couples - whether young or older. Just $4 \%$ of these individuals experience a rising trajectory, whilst around a quarter experience a falling trajectory (compared to $14 \%$ of all individuals).

Pensioners, the vast majority of whom have already retired, have the most stable income trajectories - both the lowest proportion of fluctuating trajectories and the highest proportion of flat trajectories $-40 \%$ for individuals in pensioner couples and $35 \%$ for single pensioners, compared with $24 \%$ of all individuals. Nonetheless, the majority of pensioners do not have flat trajectories and a third of pensioners have neither flat nor flat with blip trajectories. 
Table 2: Trajectory Types by Initial Life Stage ${ }^{1}$

\begin{tabular}{|c|c|c|c|c|c|c|c|}
\hline \multirow[b]{2}{*}{ Life stage $^{1}$} & \multirow[b]{2}{*}{$\begin{array}{l}\% \text { of } \\
\text { cases }\end{array}$} & \multicolumn{6}{|c|}{ Proportion experiencing different trajectory types (\%) } \\
\hline & & Flat & $\begin{array}{c}\text { Flat with } \\
\text { blip(s) }\end{array}$ & Rising & Falling & Fluct. & Other \\
\hline Children & 20.0 & 17.0 & 24.7 & 21.8 & 9.0 & 14.0 & 13.4 \\
\hline Young and single & 8.9 & 19.7 & 19.7 & 19.6 & 13.1 & 13.0 & 15.1 \\
\hline Single parent & 2.1 & 13.6 & 22.7 & 24.2 & 9.7 & 15.9 & 13.8 \\
\hline $\begin{array}{l}\text { Young couple, no } \\
\text { children }\end{array}$ & 6.7 & 30.2 & 19.3 & 4.1 & 23.1 & 10.3 & 12.9 \\
\hline $\begin{array}{l}\text { Couple with young } \\
\text { children }\end{array}$ & 10.9 & 23.3 & 26.7 & 12.5 & 13.2 & 10.6 & 13.8 \\
\hline $\begin{array}{l}\text { Couple with older } \\
\text { children }\end{array}$ & 9.7 & 21.4 & 22.3 & 24.7 & 5.8 & 15.5 & 10.3 \\
\hline $\begin{array}{l}\text { Older couple, no } \\
\text { children }\end{array}$ & 16.0 & 20.1 & 21.8 & 3.6 & 26.1 & 15.6 & 12.9 \\
\hline Older and single & 4.9 & 25.4 & 25.3 & 8.0 & 12.2 & 16.6 & 12.5 \\
\hline Pensioner couple & 10.5 & 39.9 & 24.5 & 3.5 & 15.9 & 7.2 & 9.0 \\
\hline Single pensioner & 10.3 & 34.7 & 29.0 & 5.8 & 10.6 & 8.7 & 11.1 \\
\hline All persons & 100.0 & 24.3 & 23.8 & 12.6 & 14.3 & 12.6 & 12.5 \\
\hline
\end{tabular}

Source: Own analysis using first ten waves of BHPS

Notes:

1. In the first wave of the BHPS.

Lightly shaded boxes indicate substantially lower-than-average probabilities (at least 1.5 times lower than average). Darkly shaded boxes indicate substantially higher-than-average probabilities (at least 1.5 times higher than average).

The pattern revealed in Table 2 matches prior expectations about how changes in family circumstances are likely to affect people's incomes at different stages in their life cycle. For example, many adults who are in childless couples at the beginning of the period will have children by the end of the period, which we might expect to be associated with a fall in household income. The association between key life events, such as having children, and income trajectories is examined in the next section.

In each case, the stage people are at in their lives increases the probability of experiencing the most common trajectory associated with that life stage by a factor of between 1.5-2. However, there is considerable heterogeneity in people's income trajectories. For example, an older adult in a childless couple is almost twice as likely than average to experience a falling trajectory, but the majority of people in this position experience one of the other trajectory types. 


\subsection{Income trajectories and other characteristics}

Table 3 provides a further breakdown of income trajectory type by a range of other (wave one) characteristics that might be expected to be associated with different income trajectories. There are no substantial differences in the income trajectories experienced by men and women. Most men and women live with a partner of the opposite sex - and we focus on household income, as opposed to individual incomes, assuming this is shared equally between household members. ${ }^{15}$ However, as discussed in the next section, partnership breakdown and to a lesser extent partnership formation have a differential impact on men and women's income trajectories.

There are clear differences in the pattern of trajectories experienced by age group. Older children and young adults have a relatively high proportion of rising trajectories, but also a higher proportion of unstable trajectories. For those aged between 25-44 at the beginning of the period, the overall distribution of income trajectories is similar to the average for the population as a whole, as differences according to individuals' family circumstances - for example, whether they are married and/or have children - are averaged out. (One of the advantages of focusing on life stages, as we do in this paper, is that it is possible to identify distinct groups with different patterns of income trajectories within this 'middle' age range.) The next two age groups - 45-54 and 55-64 experience the highest proportion of falling trajectories. Those aged over 65 in wave one have the most stable trajectories, though less so for the very oldest age group (aged 75 and over). The distribution of income trajectories by age group is consistent with Figure 1, although it also shows that there is a considerable amount of variation around the average.

Poor health status appears to have relatively little impact on ten wave trajectories, though individuals with a limiting illness or disability at the start of the period are slightly less likely to experience a rising trajectory and slightly more likely to experience a blipping or fluctuating trajectory.

See Rake (2000) for an analysis of women's incomes over the lifetime, including the implied size of income transfers from male to female partners. 
Table 3: Trajectory Types and Initial Characteristics

\begin{tabular}{|c|c|c|c|c|c|c|c|}
\hline \multicolumn{2}{|c|}{ \% of individuals } & \multirow{2}{*}{$\begin{array}{l}\text { Flat } \\
24.3 \\
\end{array}$} & \multirow{2}{*}{$\begin{array}{c}\text { Flat with } \\
\text { blip(s) }\end{array}$} & \multirow{2}{*}{$\begin{array}{r}\text { Rising } \\
12.6\end{array}$} & \multirow{2}{*}{$\begin{array}{c}\text { Falling } \\
14.3 \\
\end{array}$} & \multirow{2}{*}{$\begin{array}{r}\text { Fluct. } \\
12.6\end{array}$} & \multirow{2}{*}{$\begin{array}{r}\text { Other } \\
12.5 \\
\end{array}$} \\
\hline All persons & & & & & & & \\
\hline \multirow[t]{2}{*}{ Gender } & Male & 22.7 & 23.6 & 13.4 & 14.5 & 13.0 & 12.8 \\
\hline & Female & 25.7 & 24.0 & 11.8 & 14.0 & 12.3 & 12.2 \\
\hline \multirow[t]{9}{*}{ Age } & $0-10$ & 20.7 & 27.3 & 18.3 & 10.5 & 11.5 & 11.7 \\
\hline & $11-15$ & 8.7 & 19.2 & 27.8 & 6.4 & 19.0 & 19.0 \\
\hline & $16-24$ & 16.2 & 21.9 & 19.7 & 11.6 & 16.9 & 13.7 \\
\hline & $25-34$ & 25.4 & 21.4 & 12.9 & 16.9 & 9.0 & 14.4 \\
\hline & $35-44$ & 29.3 & 21.8 & 16.2 & 8.5 & 13.1 & 11.1 \\
\hline & $45-54$ & 17.3 & 22.5 & 9.2 & 22.8 & 15.2 & 13.0 \\
\hline & $55-64$ & 19.7 & 26.2 & 3.7 & 21.6 & 17.2 & 11.7 \\
\hline & $65-74$ & 41.6 & 25.0 & 4.4 & 13.1 & 7.3 & 8.7 \\
\hline & 75 and over & 28.2 & 30.4 & 5.8 & 12.8 & 8.5 & 14.4 \\
\hline \multirow[t]{2}{*}{ Health status } & healthy & 24.3 & 23.6 & 12.9 & 14.1 & 12.3 & 12.8 \\
\hline & health problems & 24.0 & 26.0 & 9.8 & 15.4 & 15.4 & 9.5 \\
\hline \multirow{8}{*}{$\begin{array}{l}\text { Economic } \\
\text { Status }\end{array}$} & self-employed & 9.7 & 17.7 & 14.5 & 10.7 & 26.3 & 21.0 \\
\hline & all in FT employment & 28.4 & 21.5 & 9.7 & 19.7 & 8.3 & 12.5 \\
\hline & $1 \mathrm{FT}+1 \mathrm{PT}$ & 22.4 & 23.9 & 20.1 & 15.3 & 8.4 & 9.9 \\
\hline & $1 \mathrm{FT}+1$ not working & 17.2 & 27.8 & 11.3 & 18.9 & 13.0 & 11.9 \\
\hline & PT employment only & 18.3 & 19.0 & 10.2 & 18.0 & 22.0 & 12.5 \\
\hline & head/ spouse $60+$ & 38.6 & 28.0 & 5.3 & 9.4 & 8.4 & 10.3 \\
\hline & head/spouse unemp. & 21.4 & 24.8 & 19.0 & 6.4 & 18.1 & 10.3 \\
\hline & Other & 17.0 & 25.8 & 27.0 & 6.2 & 10.3 & 13.8 \\
\hline \multirow[t]{4}{*}{ Tenure } & outright owner & 28.2 & 24.6 & 5.7 & 16.6 & 13.4 & 11.5 \\
\hline & mortgagor & 23.8 & 21.0 & 13.0 & 15.7 & 12.4 & 14.1 \\
\hline & social tenant & 22.9 & 30.5 & 17.3 & 9.1 & 10.8 & 9.5 \\
\hline & private tenant & 20.7 & 18.9 & 15.3 & 14.3 & 16.9 & 13.9 \\
\hline \multirow[t]{7}{*}{ Income group } & bottom quintile & 27.9 & 25.9 & 19.9 & 0.8 & 13.2 & 12.2 \\
\hline & 2nd quintile & 22.7 & 25.8 & 20.0 & 7.3 & 12.4 & 11.8 \\
\hline & 3rd quintile & 14.4 & 23.2 & 15.3 & 16.6 & 16.1 & 14.3 \\
\hline & 4th quintile & 21.2 & 25.4 & 7.0 & 19.9 & 12.5 & 13.9 \\
\hline & top quintile & 35.8 & 18.8 & 1.5 & 25.3 & 8.7 & 10.0 \\
\hline & poor in at least once & 15.4 & 24.6 & 12.1 & 14.2 & 19.3 & 14.4 \\
\hline & rich in at least once & 22.3 & 21.0 & 11.8 & 15.6 & 16.0 & 13.3 \\
\hline
\end{tabular}

Source: Own analysis using first ten waves of BHPS

Note: Lightly shaded boxes indicate substantially lower-than-average probabilities (at least 1.5 times lower than average). Darkly shaded boxes indicate substantially higher-than-average probabilities (at least 1.5 times higher than average). 
Individuals in households that rely on income from self-employment or parttime work have the most unstable income trajectories - both a low proportion of flat trajectories and a high proportion of fluctuating trajectories. People living in unemployed households also have a high proportion of fluctuating trajectories, perhaps reflecting the no pay-low pay cycle, but also a higher-than-average proportion of rising trajectories. Conversely, individuals living in retired households and individuals in households with all adults in full-time employment have the most stable trajectories. The "other" category, which includes many single parents and other economically inactive households, are the most upwardly mobile.

As expected, individuals who start the period in the poorest quintile group are more likely to experience rising trajectories and less likely to experience falling trajectories - and vice-versa for those starting in the richest quintile group. Individuals in the top and bottom income groups are restricted in their movement in one direction, so it is not surprising that both groups also have a higher proportion of flat trajectories. It is the asymmetries in the pattern across income groups that are of greater interest. We might, for example, expect a Ushaped distribution of flat trajectories, with the prevalence of flat trajectories least among individuals starting in the middle of the income distribution in wave one. However, the distribution of flat trajectories is in fact J-shaped; the poorest individuals in wave one have a lower proportion of flat trajectories and a higher proportion of fluctuating and blipping trajectories than the richest, suggesting that the position of richer individuals in the income distribution is less volatile than that of poorer individuals. ${ }^{16}$ An alternative approach is to compare those who have been in the bottom income group for at least one wave out of the ten with those who have been in the top income group for at least one wave. This also shows that those who have experienced at least one wave in poverty - the "ever poor" - are much less likely to have flat trajectories and much more likely to have fluctuating trajectories than the "ever rich".

\subsection{How important are initial life stages in understanding income trajectories}

One way to assess the importance of life stages in understanding income dynamics is to examine the significance of the correlation between individuals' life stage (in wave one) and subsequent income trajectories. Table A2 in the Appendix reports the results from a series of logit regressions of the probability of experiencing each income trajectory as a function of individuals' initial

16 Incomes are more spread out towards the top of the income distribution, so movements between percentiles require larger absolute (though not necessarily proportional) changes in income for individuals from higher income groups, compared with those from lower income groups. 
characteristics. The regression results confirm the significance of the associations revealed by the bi-variate analysis reported in Table 2 . There is a highly significant association between life stages and income trajectories and in almost all cases these associations remain significant even when the other characteristics listed in Table 3 are controlled for. For example, single parents in wave one are significantly more likely to experience a rising income trajectory than adults in couples with young children - the reference category - and this is only partly explained by their lower initial position in the income distribution (which is also associated with a greater likelihood of experiencing a falling trajectory. On the other hand, young couples without children are not significantly more likely to experience a falling income trajectory after controlling for their initial income. The implication is that the main reason this group experiences a high proportion of falling trajectories is that they tend to have higher incomes to start with (and are, therefore, more vulnerable to a fall in income), rather than anything specifically to do with this life stage.

\section{Event Analysis}

Life stages provide a useful analytical tool for helping to understand individuals' income trajectories. However, the amount of the variation in income trajectories they account for is still relatively small. Life stages matter primarily because they increase the probability that an individual will experience certain life events over the next few years, which in turn may have financial repercussions. For example, many young and single adults are likely to form partnerships over the next ten years and many couples without children are likely to have children. It makes sense, therefore, to examine directly the impact of these events on people's income trajectories in order to explain more of the variation in income trajectories. It is to this that we turn in this section. In particular, we look at which life cycle events are most closely associated with each of the six types of income trajectory.

\subsection{Classification of events}

The life cycle events we consider are:

$>\quad$ Formation of a new partnership: including marriage or cohabitation;

$>$ Partnership breakdown: divorce, separation, or break up of a cohabiting union;

$>\quad$ Having children: includes joining a household with a child aged five or under;

$>\quad$ Children becoming independent: reaching 18 (or 16 and either married or no longer in full-time education), though not necessarily leaving home; 
$>\quad$ Leaving the family home; ${ }^{17}$

$>$ Onset of a limiting illness or disability lasting two or more consecutive waves;

$>$ Retirement: retiring during the period and still retired at the end of the period, based on individuals' self-reported economic status;

$>$ Widowhood.

In each case, these events are assumed to impact on the whole household. So, for example, an individual can experience the event of retirement if their partner retires and children of single parents can experience partnership formation if their mother re-partners. Unlike the life stages, these events are not mutually exclusive - an individual may experience more than one of these events during the course of the ten waves (or the same event on more than one occasion). We exclude events that occur in waves 9 and 10 since they would not have had time to have an impact on people's income trajectories over the ten wave period that we observe.

The proportion of individuals experiencing each of these events is shown in Table 4. As expected, the probability of experiencing an event varies widely between life stages. For example, over 70 per cent of individuals who start out as young adults in childless couples have children by the end of the period, compared to $25 \%$ of young and single adults, $12 \%$ of single parents, and close to zero for most other life stages. Around half of our sample did not experience any of the events listed in Table 4 over this ten year period in their lives. ten). 
Table 4: Prevalence of Life Cycle Events by Initial Life Stage

\begin{tabular}{|c|c|c|c|c|c|c|c|c|c|c|}
\hline$\%$ of individuals & Child & $\begin{array}{c}\text { Young and } \\
\text { single }\end{array}$ & $\begin{array}{l}\text { Single } \\
\text { parent }\end{array}$ & $\begin{array}{l}\text { Young } \\
\text { couple, no } \\
\text { children }\end{array}$ & $\begin{array}{c}\text { Couple } \\
\text { with young } \\
\text { children }\end{array}$ & $\begin{array}{l}\text { Couple with } \\
\text { older } \\
\text { children }\end{array}$ & $\begin{array}{c}\text { Older } \\
\text { couple, } \\
\text { no } \\
\text { children }\end{array}$ & $\begin{array}{l}\text { Older } \\
\text { and } \\
\text { single }\end{array}$ & $\begin{array}{l}\text { Pens. } \\
\text { couple }\end{array}$ & $\begin{array}{l}\text { Single } \\
\text { pens. }\end{array}$ \\
\hline Left family home & 8.7 & 43.6 & 6.3 & 2.8 & 1.0 & 0.0 & 0.0 & 0.0 & 0.0 & 0.0 \\
\hline Formed partnership & 15.9 & 61.0 & 39.8 & 11.8 & 4.9 & 2.4 & 2.4 & 13.3 & 0.3 & 3.9 \\
\hline Split up & 12.5 & 10.7 & 7.1 & 17.1 & 12.7 & 8.7 & 3.5 & 2.9 & 1.6 & 1.6 \\
\hline Had child & 7.4 & 25.1 & 12.3 & 68.3 & 6.0 & 7.5 & 3.8 & 1.5 & 0.0 & 0.5 \\
\hline Children independent & 5.9 & 0.3 & 24.7 & 0.4 & 1.0 & 57.3 & 0.3 & 0.5 & 0.0 & 0.0 \\
\hline Disability (2+ waves) & 21.4 & 14.5 & 28.1 & 10.6 & 16.1 & 22.7 & 29.3 & 19.2 & 35.5 & 25.1 \\
\hline Retire & 1.7 & 9.5 & 3.1 & 0.7 & 1.2 & 4.8 & 49.1 & 32.7 & 43.6 & 29.0 \\
\hline Widowed & 1.2 & 0.0 & 0.0 & 0.7 & 0.8 & 1.2 & 4.0 & 0.3 & 19.1 & 2.0 \\
\hline None of above & 52.8 & 19.1 & 30.6 & 19.8 & 67.1 & 25.5 & 33.8 & 46.8 & 26.7 & 49.5 \\
\hline
\end{tabular}

Source: Own analysis using BHPS.

1. Life cycle events experienced between waves 1-8 (inclusive).

Darkly shaded boxes indicate substantially higher-than-average probabilities (at least 1.5 times higher than average). 


\subsection{The importance of events for income trajectories}

Our approach to analysing the impact of events on income trajectories is similar to that adopted in research on identifying 'trigger' events underpinning poverty transitions (see, for example, Jenkins and Rigg, 2001). But, rather than looking at the association between events and concurrent movements into or out of poverty, we look at the association between events and ten-wave income trajectories.

The importance of each event is assessed using three types of statistic:

i. conditional probability: the probability of experiencing a given income trajectory conditional on the event occurring;

ii. event prevalence: the proportion of all individuals experiencing each event;

iii. share statistic: the proportion of individuals with a given income trajectory who have experienced a particular event; this is the product of the conditional probability and the event prevalence.

The purpose of this analysis is to identify events that are associated with a high probability of experiencing a particular trajectory type (i.e. high conditional probabilities) and that are relatively common. For many of the events, we examine their effects on different sub-groups - distinguishing, for example, between the impact of partnership breakdown on men, women, and children.

Arguably, the impact of an event might be more accurately assessed by focusing on changes in income in the years immediately surrounding that event. A tenyear observation window may well capture a number of events (possibly related), and it may be difficult to distinguish the principal event driving income changes. Thus, we repeated our analysis using a four-year classification of income trajectories similar to that used in Gardiner and Hills (1999). ${ }^{18}$ The results for four-wave income trajectories were broadly similar to those based on the ten-wave trajectories (see Table A3 in the Appendix); below we refer only to the main differences between the two sets of results.

There are also methodological benefits to looking at shorter income trajectories. Firstly, we can increase sample size, by including respondents who appear for at least four, but not all ten, waves. Secondly, we can focus specifically on the period immediately prior to and after the event (whereas in the ten wave analysis, the event may occur at any point - up to and including wave eight - during the ten wave period). The base year for this analysis is the wave prior before the event being observed and our mini-trajectories are based on what happens to these individuals' incomes over the three following waves. 
Table 5 shows for each life cycle event the proportion of people experiencing different income trajectories. Certain events, notably having children and retirement, are clearly associated with a higher proportion of falling trajectories. In both cases, around a quarter of people in these households experience a falling trajectory, compared with $14 \%$ of all persons in our sample. These individuals are also more likely to experience a downward blip (over four waves) and less likely to experience a rising trajectory (over four and ten waves).

Households who have children are more likely to reduce their employment activity, compared to similar households who do not have children. But, even those households that do not reduce their economic activity experience a higher proportion of falling trajectories, perhaps because parents work reduced hours or move to more flexible, but less well paid jobs to fit around their parenting responsibilities and/or because children increase the demands on the household budget. ${ }^{19}$ There is some evidence that new parents in higher income groups are more likely to reduce their economic activity, because it is more likely that both parents are in full-time employment prior to the birth of their child.

Almost by definition, (self-reported) retirement is also associated with a fall in employment activity for many households. Those who were working in the year prior to retiring (and their co-residents) are much more likely to experience a falling income trajectory upon retirement than those who were unemployed or economically inactive. This is consistent with previous research showing that, on average, retirement is strongly associated with a decline in household income, not only in the year of retirement but also in the years around retirement, especially for those who were previously in full-time employment (Bardasi, Jenkins, and Rigg, 2002).

Other events are associated with rising trajectories, including partnership formation, children becoming independent, and leaving the family home (though not over four waves). Single mothers who form partnerships (and their dependent children), in particular, have a high proportion of rising trajectories, though single men who form partnerships also have a higher-than-average proportion of rising trajectories. scale. 
Table 5: Ten Wave Income Trajectories Associated with Different Life Cycle events ${ }^{1}$

\begin{tabular}{|c|c|c|c|c|c|c|}
\hline \% of individuals & Flat & $\begin{array}{c}\text { Flat with } \\
\text { blip(s) }\end{array}$ & Rising & Falling & Fluct. & Other \\
\hline All persons & 24.3 & 23.8 & 12.6 & 14.3 & 12.6 & 12.5 \\
\hline Left family home & 10.3 & 17.6 & 24.5 & 12.1 & 17.2 & 18.4 \\
\hline Formed partnership & 15.4 & 19.0 & 23.9 & 10.5 & 15.9 & 15.3 \\
\hline Split up & 11.9 & 21.6 & 16.7 & 14.3 & 21.4 & 14.1 \\
\hline Had child & 17.8 & 19.2 & 6.8 & 24.9 & 12.9 & 18.4 \\
\hline Children independent & 17.2 & 21.3 & 27.0 & 5.6 & 19.3 & 9.7 \\
\hline Disability (2+ waves) & 22.7 & 25.2 & 11.6 & 14.9 & 12.6 & 13.1 \\
\hline Retired & 21.9 & 24.5 & 4.1 & 25.9 & 13.0 & 10.7 \\
\hline Widowed & 25.7 & 31.4 & 7.6 & 14.0 & 10.7 & 10.6 \\
\hline None of above & 29.2 & 25.2 & 13.0 & 10.1 & 10.3 & 12.2 \\
\hline \multicolumn{7}{|l|}{ Interaction effects: } \\
\hline Left home to live with partner & 14.0 & 14.4 & 28.0 & 13.9 & 12.0 & 17.7 \\
\hline Left home - single person & 6.3 & 20.3 & 20.4 & 9.9 & 24.6 & 18.4 \\
\hline Partnership - lone mums + children & 7.1 & 23.7 & 29.1 & 10.6 & 16.9 & 12.5 \\
\hline Partnership - single women & 18.5 & 18.0 & 23.4 & 8.4 & 16.6 & 15.0 \\
\hline Partnership - men & 16.0 & 18.1 & 21.4 & 12.4 & 15.5 & 16.6 \\
\hline Split up - women \& children & 8.2 & 22.4 & 14.9 & 16.1 & 26.6 & 11.7 \\
\hline Split up - women no children & 17.2 & 15.5 & 12.8 & 15.4 & 19.4 & 19.7 \\
\hline Split up - men no children & 23.4 & 16.8 & 18.2 & 9.4 & 20.2 & 12.0 \\
\hline Split up - men with children & 3.6 & 25.3 & 29.1 & 1.4 & 16.5 & 24.0 \\
\hline Children independent - left home & 21.4 & 24.4 & 16.3 & $\mathbf{0 . 0}$ & 25.1 & 12.7 \\
\hline Children independent - at home & 15.9 & 21.5 & 28.2 & 6.5 & 18.6 & 9.3 \\
\hline Disability - retired & 29.7 & 25.0 & 8.0 & 16.3 & 9.5 & 11.5 \\
\hline Disability - prev. working & 16.6 & 24.5 & 11.6 & 19.0 & 13.6 & 14.7 \\
\hline Disability - prev. not working & 19.8 & 28.5 & 14.1 & 8.1 & 14.8 & 14.7 \\
\hline Retired - prev. working & 15.3 & 21.5 & 2.0 & 37.5 & 15.3 & 8.4 \\
\hline Retired - prev. not working & 25.0 & 26.0 & 4.8 & 20.0 & 12.0 & 12.2 \\
\hline Widowed - non-pens. & 19.0 & 37.2 & 6.1 & 11.6 & 16.7 & 9.4 \\
\hline Widowed - older women & 28.2 & 30.4 & 7.6 & 16.5 & 6.7 & 10.6 \\
\hline Widowed - older men & 27.4 & 27.6 & 8.9 & 10.8 & 13.4 & 11.9 \\
\hline
\end{tabular}

Source: Own analysis using first ten waves of BHPS

1. Probability of experiencing each income trajectory conditional upon experiencing each of the life cycle events listed in the Table.

Lightly shaded boxes indicate substantially lower-than-average probabilities (at least 1.5 times lower than average). Darkly shaded boxes indicate substantially higher-than-average probabilities (at least 1.5 times higher than average). 
Home-leavers have a higher-than-average proportion of rising trajectories over ten waves, especially those who leave home to live with a partner. Our analysis of four wave trajectories shows a much weaker association with rising trajectories and a stronger association with "other" (i.e. less stable) trajectories or even falling trajectories. This implies that leaving home is often associated with a period of instability, but that in the longer-run young adults, on average, experience rising incomes which probably have more to do with moving up the career ladder and getting married than leaving home per se.

Two factors appear to be at work within households where children become independent over the period: either their children leave home, increasing the households' equivalised income - the so-called 'empty nesters' - or they remain at home and (in some cases) contribute to the household's income. In both cases, individuals in these households experience a higher-than-average proportion of rising trajectories.

The event most strongly associated with fluctuating trajectories is partnership breakdown. However, the impact of this event varies hugely by gender and the presence of children. Women with dependent children are most adversely affected by partnership breakdown - with higher proportions of falling trajectories (over four waves) and fluctuating or "other" trajectories (over four and ten waves) compared with women and children who do not experience this event. Women without children who experience this event fare worse than women who remain with their partner, though not as badly as women with children. Men, especially those with children, have a higher-than-average proportion of rising trajectories following partnership breakdown, although these individuals also have more unstable trajectories, especially over four waves. ${ }^{20}$ This is consistent with previous research based on the first four waves of the BHPS showing that partnership breakdown is associated with a substantial decline in income for women and children, but has a less adverse impact on men (Jarvis and Jenkins, 1999). Extending the analysis to ten waves of the BHPS suggests that partnership breakdown has a prolonged destabilising effect on incomes for both men and women, that women and children continue to fare worse, on average, but that they have fewer falling trajectories over ten waves than over four waves. Indeed, a significant minority of women experience rising trajectories over the longer period, as they increase their employment activity and/or re-partner.

Child maintenance payments, whilst included in the incomes of the recipients, are not deducted from the incomes of those who make these payments - in most cases, the fathers. Thus, the incomes of men who have experienced partnership breakdown will tend to be over-estimated. 
Widowhood is most strongly associated with a blipping trajectory over ten waves, especially for non-pensioners. Over four waves, younger widows or widowers experience a high proportion of falling trajectories, with the implication that many of these recover their position in the income distribution over the longer run. For pensioners, widowhood appears to have relatively little impact on their income trajectories. ${ }^{21}$ If anything, older widowers have slightly more favourable trajectories than older widows, in line with previous research by Zaidi (2001), but sample sizes are too small to draw firm conclusions.

The onset of a long-term illness or disability does not appear to have a very significant impact on income trajectories. One possible interpretation is that the welfare state is effective in protecting people against the adverse financial effects of ill-health and disability. However, a more plausible interpretation is that adults who experience ill-health or disability are often disadvantaged to start with - the "selection effect" identified in Jenkins and Rigg (2003) - and are consequently constrained in the degree of downward movement. Compared with other adults, those who experience the onset of a long-term illness or disability are less likely to be economically active and more likely to be closer to the bottom of the income distribution prior to onset. Consistent with this explanation, those individuals who were in work prior to onset (around two fifths of those who experienced this event), did have a higher-than-average proportion of falling trajectories. This issue is discussed further in the next section.

Although many of these events are related to specific income trajectories in the way we might expect, there is a large amount of heterogeneity in people's income trajectories following each of these life cycle events. For example, individuals who retire are twice as likely to experience a falling income trajectory over the ten waves, but over three quarters of them experienced one of the other trajectory types. The pattern is similar for other events. Typically, each life cycle event increases the probability of experiencing a particular income trajectory - either rising, falling, blipping, or fluctuating, depending on the event - by a factor of approximately two, but most individuals will still follow one of the other trajectory types.

Part of this variation can be explained by differences in the initial characteristics of individuals. For example, those who were working prior to retirement are nearly three times more likely than average to experience a falling income

$21 \quad$ Note that reductions in household income following widowhood do not necessarily lead to reductions in equivalised income since there is also a reduction in household need. 
trajectory, whereas those who were not previously working are only one and a half times more likely to experience a falling trajectory. More generally, those who were relatively well off to start with are often most adversely affected by 'negative' events, because they have more to lose. Gender differences also account for some of this variation - women benefit more financially from partnership formation and are most adversely affected by partnership breakdown and (possibly) widowhood. However, even when these more obvious factors are taken into account, there remains a large amount of heterogeneity. Clearly, the impact of an event depends on an individual's (or their household's) particular circumstances at the time and how they respond to that event, both of which will vary from one person (or household) to the next. For example, the impact of an individual retiring depends on whether they have an occupational pension and, if so, how generous it is and whether their partner, if they have one, also retires over this period, among other factors.

So far, we have examined the probability of experiencing a particular income trajectory conditional upon experiencing a particular event. From the perspective of an individual about to experience an event, that event can be considered important if it has a relatively high conditional probability. But, from an aggregate perspective, the importance of an event also depends on how prevalent it is. An event may have a major impact on the incomes of those who experience it, but if the event is rare, then it is unlikely to explain much of the overall variation in income trajectories across the population as a whole.

The event prevalence rates and share statistics by trajectory type are shown in Table 6 . The share statistic shows, for each trajectory type, the proportion of individuals who have experienced each of the events. It does not necessarily follow that a high share statistic means that an event is important in explaining why people follow that particular income trajectory. Events that have a very high prevalence rate, such as the onset of disability, may have a relatively high share statistic, even though there is only a weak or non-existent association with particular income trajectories. A combination of a relatively high share statistic and a relatively high conditional probability does, however, provide a reasonable indication that an event is important from an aggregate perspective. These cases are highlighted in Table 6. 
Table 6: Aggregate Importance of Life Cycle Events for Income Trajectories $^{1}$

\begin{tabular}{l|c|cccccc}
\hline \hline \% of individuals & Prevalence & Flat & $\begin{array}{c}\text { Flat with } \\
\text { blip(s) }\end{array}$ & Rising & Falling & Fluct. & Other \\
\hline Left family home & 6.1 & 2.6 & 4.5 & 11.8 & 5.2 & 8.3 & 9.0 \\
Formed partnership & 12.5 & 7.9 & 9.9 & $\mathbf{2 3 . 7}$ & 9.2 & 15.7 & 15.3 \\
Split up & 8.0 & 3.9 & 7.3 & 10.6 & 8.0 & 13.6 & 9.1 \\
Had child & 10.6 & 7.8 & 8.6 & 5.8 & $\mathbf{1 8 . 6}$ & 10.9 & 15.7 \\
Children independent & 7.5 & 5.3 & 6.7 & $\mathbf{1 6 . 0}$ & 2.9 & 11.4 & 5.8 \\
Disability (2+ waves) & 22.8 & 21.3 & 24.1 & 21.0 & 23.8 & 22.8 & 23.9 \\
Retired & 18.9 & 17.1 & 19.5 & 6.2 & $\mathbf{3 4 . 4}$ & 19.5 & 16.2 \\
Widowed & 3.4 & 3.6 & 4.4 & 2.0 & 3.3 & 2.9 & 2.9 \\
None of above & 39.6 & 47.6 & 41.9 & 41.1 & 28.0 & 32.6 & 38.7 \\
\hline \hline
\end{tabular}

Source: Own analysis using first ten waves of BHPS

1. Probability of having experienced a particular life cycle event for individuals on the different types of income trajectory.

Darkly shaded boxes indicate both a relatively high conditional probability and a relatively high share statistic.

From an aggregate perspective, the most important life cycle event associated with falling trajectories is retirement, followed by having children. Together, these events are experienced by around $30 \%$ of our sample, but by $55 \%$ of those with a falling income trajectory. In the case of rising trajectories, the most important events are partnership formation and children becoming independent. Together these events were experienced by around $20 \%$ of all individuals in our sample, but by $40 \%$ of those with rising income trajectories.

Whilst partnership breakdown is strongly associated with fluctuating income trajectories over ten waves, this event is not very prevalent, so it only accounts for a relatively small share of all fluctuating trajectories. Other nondemographic factors, such as reliance on income from self-employment or parttime employment would appear to be more important. Widowhood accounts for a very small share of blipping trajectories, because of the very low prevalence of this event. Overall, life cycle events account for a substantial proportion of rising and falling income trajectories, but these events (or the absence of them) are only weakly associated with the other types of income trajectory. 


\section{Poverty and the Life Cycle}

So far, we have explored the influence of life cycle factors across the entire income distribution. However, from a policy perspective, income trajectories are probably of greater concern if they involve movements into or out of poverty (periods of relative want and plenty in Rowntree's terminology). For example, an individual who retires and experiences a decline in income that moves them from the top to the middle of the income distribution will attract less policy concern than a retiree who experiences a fall in income that puts them below the (relative) poverty line. This section examines the association between life cycle factors and individuals' experiences of poverty. Are certain events of greater or lesser importance when focusing on income trajectories in the lower part of the income distribution?

In order to analyse the impact of life cycle factors on poverty, we consider a more detailed breakdown of our six income trajectories in order to distinguish trajectories that involve movements into or out of poverty. For example, we distinguish between falling trajectories that lead to poverty and those that do not, between blips into poverty and blips out of poverty. ${ }^{22}$ The poverty line used in this analysis is the bottom fifth (or quintile) of equivalised household incomes. $^{23}$

Low income observations that are part of rising trajectories, blips into poverty, or other one-off or occasional poverty might be considered less problematic than others. They are consistent with either transitory low income or low income that the individual appears to have escaped from by the end of the period. By contrast, low income observations that are part of falling trajectories, blips out of poverty, or recurrent poverty experiences might be considered more problematic, as would the 'flat poor' or persistently poor. Previous research using four waves of the BHPS has shown that most low income observations around $80 \%$ - are part of more problematic income trajectories (Gardiner and Hills, 1999). Our research shows that over ten waves, it is still the case that

22 The categories are broadly the same as those used in Gardiner and Hills (1999). The definitions are adjusted in some cases since we are using ten, rather than four, waves of data. For example, we consider an income trajectory to be non-problematic if an individual is poor for two or less waves out of ten, as opposed to one wave or less out of four.

23 This corresponds closely to the most commonly used relative poverty line, defined as $60 \%$ of median equivalised household income. Throughout the 1990s, between 17$18 \%$ of individuals fell below this income threshold on the before housing costs measure (DWP, 2002). 
three quarters of low income observations are part of more problematic income trajectories (see Table 7).

Table 7: Breakdown of Poverty-Related Income Trajectories

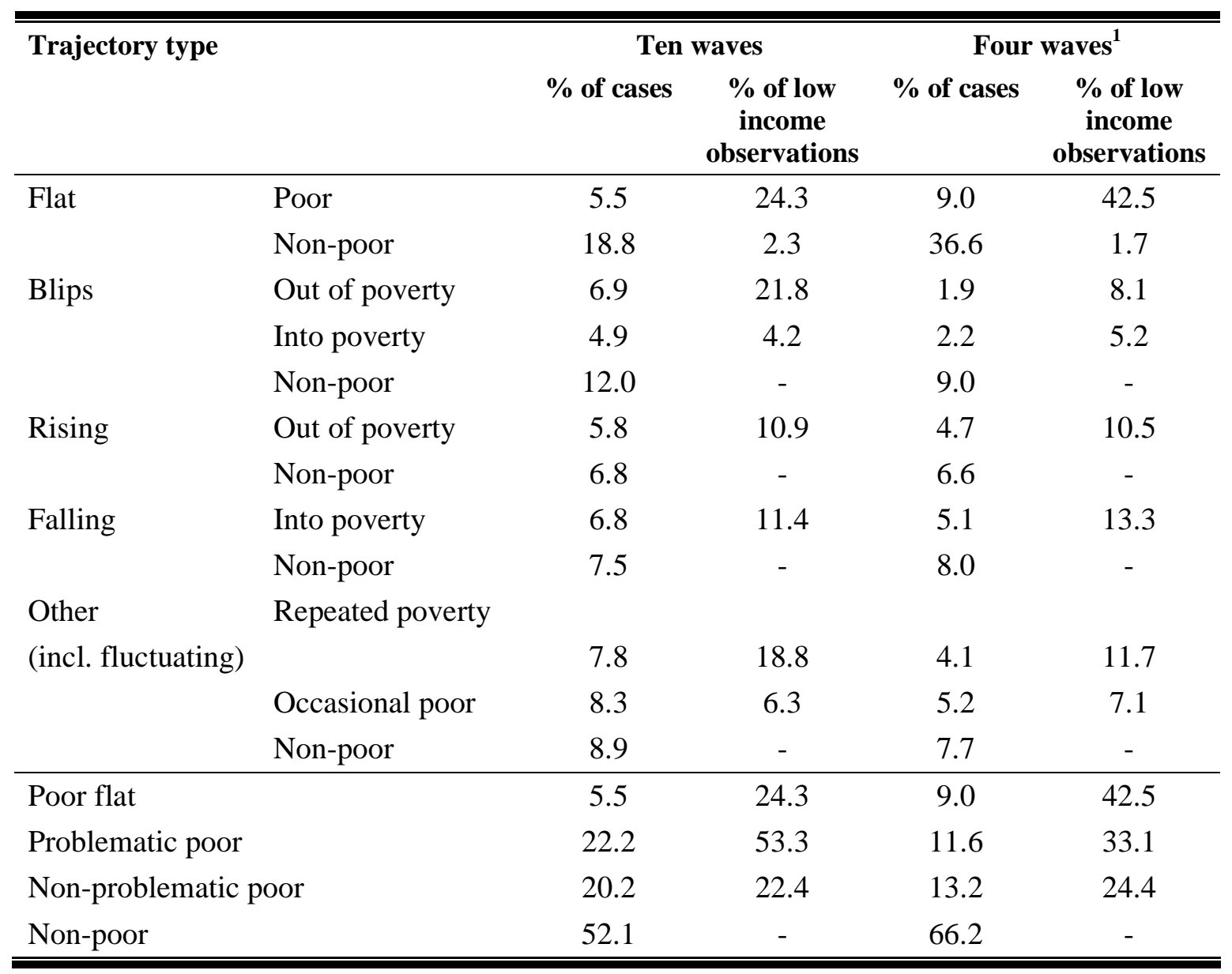

Source: Own analysis using first ten waves of BHPS.

1. Waves 1-4 for individuals with non-missing income for waves 1-10.

Although there are fewer cases involving individuals who remain in or close to poverty throughout a ten year period (i.e. flat poor), there are a higher proportion of low income observations from other problematic trajectories - in particular individuals who are blipping out of poverty or experiencing recurrent poverty. Thus, there is no evidence that income mobility reduces the extent of problematic poverty when looked at over a longer time-frame. If someone is observed to be in poverty at a particular point in time, the chances are they are experiencing a problematic income trajectory that will extend over a period of at least ten years. This is an interesting result in itself; it also provides a justification for focusing on "poor flat" and other "problematic" trajectories since these account for most low income observations. 
Table 8 shows the proportion of individuals following the different "povertyrelated' trajectories. The results are broken down by life stage (in wave one). This shows, for example, that an individual who is a single parent in wave one is not only more likely to be on a rising trajectory but is also more likely to be climbing out of poverty than others who are on a rising trajectory. Just under a half of all individuals on rising income trajectories are rising out of poverty, but over two thirds of lone parents who are on a rising trajectory are rising out of poverty. Young adults in childless couples, on the other hand, are more likely to be on a falling trajectory, but much less likely to be falling into poverty than other individuals also on a falling trajectory. This reflects the different starting points of these groups. Single parents are over-represented in the lower part of the income distribution (and so are more likely to be rising out of poverty), whilst young adults in childless couples are concentrated near the top of the income distribution (and so are less likely to fall into poverty).

Table 9 shows the same 'poverty-related' trajectory types by life cycle event. Whilst having children is associated with a higher-than-average proportion of falling trajectories, most individuals who experience this event are relatively well off to start with and do not end up in poverty. However, most of those who are affected by partnership breakdown and who experience a falling trajectory do fall into poverty. Thus, although having children is more likely than partnership breakdown to be associated with a falling income trajectory (25\% of cases versus $14 \%$ ), those who experience partnership breakdown are at greater risk of falling into poverty (11\% of cases versus $7 \%$ ). Whilst those experiencing a disability (and their co-residents) are no more likely than average to experience a falling income trajectory than other households, they are more likely to be on a problematic income trajectory, because they are often in or close to poverty prior to the onset of disability, as noted in the previous section. If they are on a flat trajectory, they are most likely to be "flat poor", if they are on a falling trajectory, they are most likely to be falling into poverty and if they are on a blipping trajectory, they are most likely to be blipping out of poverty. Retirees are spread more evenly across the income distribution and are split equally between the "falling into poverty" and the "falling non-poor" trajectories. 
Table 8: Detailed Breakdown of Ten-Wave Trajectory Types by Initial Life Stage

\begin{tabular}{|c|c|c|c|c|c|c|c|c|c|c|c|c|}
\hline & & $\begin{array}{c}\text { All } \\
\text { persons }\end{array}$ & Child & $\begin{array}{l}\text { Young } \\
\text { and } \\
\text { single }\end{array}$ & $\begin{array}{l}\text { Single } \\
\text { parent }\end{array}$ & $\begin{array}{l}\text { Young } \\
\text { couple, no } \\
\text { children }\end{array}$ & $\begin{array}{c}\text { Couple } \\
\text { with } \\
\text { young } \\
\text { children }\end{array}$ & $\begin{array}{c}\text { Couple } \\
\text { with } \\
\text { older } \\
\text { children }\end{array}$ & $\begin{array}{c}\text { Older } \\
\text { couple, } \\
\text { no } \\
\text { children }\end{array}$ & $\begin{array}{l}\text { Older } \\
\text { and } \\
\text { single }\end{array}$ & $\begin{array}{l}\text { Pens. } \\
\text { couple }\end{array}$ & $\begin{array}{c}\text { Single } \\
\text { pens. }\end{array}$ \\
\hline \multirow[t]{2}{*}{ Flat } & Poor & 5.5 & 4.3 & 0.1 & 10.7 & 1.3 & 5.3 & 1.8 & 1.5 & 5.7 & 12.5 & 16.7 \\
\hline & Non-poor & 18.8 & 12.8 & 19.5 & 3.0 & 29.0 & 18.0 & 19.6 & 18.5 & 19.6 & 27.4 & 18.0 \\
\hline \multirow[t]{3}{*}{ Blips } & Out of poverty & 6.9 & 9.8 & 1.3 & 12.7 & 1.4 & 9.3 & 2.7 & 2.4 & 6.6 & 11.7 & 12.0 \\
\hline & Into poverty & 4.9 & 5.2 & 3.3 & 3.9 & 2.2 & 4.2 & 4.2 & 5.9 & 8.0 & 5.7 & 5.3 \\
\hline & Non-poor & 12.0 & 9.7 & 15.1 & 6.2 & 15.7 & 13.2 & 15.3 & 13.5 & 10.7 & 7.0 & 11.7 \\
\hline \multirow[t]{2}{*}{ Rising } & Out of poverty & 5.8 & 11.6 & 5.9 & 17.0 & 0.7 & 5.7 & 6.8 & 2.5 & 4.2 & 2.0 & 4.6 \\
\hline & Non-poor & 6.8 & 10.2 & 13.6 & 7.2 & 3.5 & 6.8 & 18.0 & 1.1 & 3.8 & 1.6 & 1.2 \\
\hline \multirow[t]{2}{*}{ Falling } & Into poverty & 6.8 & 5.3 & 3.4 & 6.8 & 3.9 & 5.9 & 2.3 & 12.4 & 7.5 & 9.1 & 8.4 \\
\hline & Non-poor & 7.5 & 3.7 & 9.7 & 2.9 & 19.3 & 7.3 & 3.5 & 13.7 & 4.7 & 6.9 & 2.2 \\
\hline \multirow[t]{3}{*}{ Other* } & $\begin{array}{l}\text { Repeated } \\
\text { poverty }\end{array}$ & 7.8 & 8.8 & 5.2 & 14.7 & 2.8 & 8.9 & 5.1 & 8.2 & 8.8 & 6.8 & 11.5 \\
\hline & $\begin{array}{l}\text { Occasional } \\
\text { poor }\end{array}$ & 8.3 & 10.7 & 10.7 & 12.3 & 8.5 & 6.1 & 8.9 & 9.0 & 13.0 & 3.6 & 4.1 \\
\hline & Non-poor & 8.9 & 8.0 & 12.1 & 2.8 & 11.9 & 9.4 & 11.8 & 11.3 & 7.4 & 5.8 & 4.3 \\
\hline \multicolumn{2}{|c|}{ Poor flat } & 5.5 & 4.3 & 0.1 & 10.7 & 1.3 & 5.3 & 1.8 & 1.5 & 5.7 & 12.5 & 16.7 \\
\hline \multicolumn{2}{|c|}{ Problematic poor } & 22.2 & 24.2 & 9.9 & 35.3 & 8.0 & 24.9 & 10.5 & 23.4 & 24.7 & 28.2 & 34.4 \\
\hline \multicolumn{2}{|c|}{ Non-problematic poor } & 20.2 & 28.0 & 20.3 & 33.1 & 11.4 & 16.9 & 19.8 & 17.6 & 26.9 & 15.3 & 18.1 \\
\hline \multicolumn{2}{|c|}{ Non-poor } & 52.1 & 43.6 & 69.7 & 20.9 & 79.3 & 52.9 & 67.9 & 57.5 & 42.6 & 44.0 & 30.7 \\
\hline
\end{tabular}

Source: Own analysis using first ten waves of BHPS.

* Includes fluctuating trajectories

Lightly shaded boxes indicate substantially lower-than-average probabilities (at least 1.5 times lower than average). Darkly shaded boxes indicate substantially higher-than-average probabilities (at least 1.5 times higher than average). 
Table 9: Detailed Breakdown of Ten-Wave Trajectory Types by Life Cycle Event

\begin{tabular}{|c|c|c|c|c|c|c|c|c|c|c|c|}
\hline & & $\begin{array}{c}\text { All } \\
\text { persons }\end{array}$ & $\begin{array}{c}\text { Left } \\
\text { home }\end{array}$ & Partnered & Split up & $\begin{array}{l}\text { Had } \\
\text { child }\end{array}$ & $\begin{array}{c}\text { Independent } \\
\text { children }\end{array}$ & $\begin{array}{c}\text { Disability } \\
(2+\text { waves })\end{array}$ & Retired & Widowed & $\begin{array}{c}\text { None of these } \\
\text { events }\end{array}$ \\
\hline \multirow[t]{2}{*}{ Flat } & Poor & 5.5 & 0.5 & 2.5 & 3.7 & 0.8 & 1.2 & 8.5 & 6.4 & 8.9 & 5.4 \\
\hline & Non-poor & 18.8 & 9.7 & 12.8 & 8.2 & 17.0 & 15.9 & 14.2 & 15.5 & 16.8 & 23.8 \\
\hline \multirow[t]{3}{*}{ Blips } & Out of poverty & 6.9 & 2.9 & 7.0 & 10.4 & 6.5 & 2.8 & 11.8 & 7.1 & 11.2 & 5.4 \\
\hline & Into poverty & 4.9 & 3.6 & 1.8 & 2.4 & 1.8 & 4.7 & 5.1 & 7.2 & 9.3 & 4.9 \\
\hline & Non-poor & 12.0 & 11.1 & 10.2 & 8.8 & 11.0 & 13.8 & 8.4 & 10.2 & 10.9 & 14.8 \\
\hline \multirow[t]{2}{*}{ Rising } & Out of poverty & 5.8 & 9.9 & 12.3 & 9.7 & 4.1 & 7.6 & 7.6 & 1.8 & 5.8 & 6.0 \\
\hline & Non-poor & 6.8 & 14.5 & 11.6 & 7.0 & 2.7 & 19.4 & 4.0 & 2.3 & 1.7 & 7.0 \\
\hline \multirow[t]{2}{*}{ Falling } & Into poverty & 6.8 & 4.6 & 4.5 & 11.4 & 7.2 & 2.3 & 8.8 & 13.9 & 9.5 & 4.1 \\
\hline & Non-poor & 7.5 & 7.5 & 6.0 & 2.9 & 17.6 & 3.3 & 6.0 & 12.0 & 4.5 & 6.0 \\
\hline \multirow[t]{3}{*}{ Other* } & $\begin{array}{l}\text { Repeated } \\
\text { poverty }\end{array}$ & 7.8 & 7.8 & 6.8 & 12.1 & 8.4 & 6.0 & 10.9 & 10.1 & 5.7 & 6.5 \\
\hline & $\begin{array}{l}\text { Occasional } \\
\text { poor }\end{array}$ & 8.3 & 14.4 & 13.0 & 13.8 & 9.1 & 10.3 & 7.5 & 9.0 & 7.6 & 6.9 \\
\hline & Non-poor & 8.9 & 13.3 & 11.4 & 9.6 & 13.8 & 12.6 & 7.3 & 4.6 & 8.0 & 9.2 \\
\hline \multicolumn{2}{|c|}{ Poor flat } & 5.5 & 0.5 & 2.5 & 3.7 & 0.8 & 1.2 & 8.5 & 6.4 & 8.9 & 5.4 \\
\hline \multicolumn{2}{|c|}{ Problematic poor } & 22.2 & 15.4 & 18.3 & 33.8 & 22.4 & 11.6 & 32.7 & 32.0 & 27.5 & 16.7 \\
\hline \multicolumn{2}{|c|}{ Non-problematic poor } & 20.2 & 27.9 & 27.1 & 26.4 & 15.3 & 22.6 & 21.0 & 20.7 & 26.1 & 19.1 \\
\hline \multicolumn{2}{|c|}{ Non-poor } & 52.1 & 56.1 & 52.1 & 36.0 & 61.6 & 64.6 & 37.8 & 40.9 & 37.5 & 58.7 \\
\hline
\end{tabular}

Source: Own analysis using first ten waves of BHPS

* Includes fluctuating trajectories

Lightly shaded boxes indicate substantially lower-than-average probabilities (at least 1.5 times lower than average). Darkly shaded boxes indicate substantially higher-than-average probabilities (at least 1.5 times higher than average).- 


\section{Overall Importance of the Life Cycle}

This section examines how much of the overall variation in income trajectories can be accounted for by life cycle factors. How important is the life cycle in helping to understand income dynamics over a ten year period? By way of a benchmark, we compare the impact of life cycle factors - both the life stage of the individual (in wave one) and the life cycle events they experience over the period - with the impact of labour market factors.

Labour market factors include the wave one labour market status of the household as well as changes in household labour market activity over the period. Life cycle and labour market events are not mutually exclusive. Many, though not all, of the life cycle events affect incomes indirectly through their impact on employment. For instance, mothers typically reduce their employment activity when they have children and (self-reported) retirement is usually, though not always, associated with a reduction in employment activity. Thus, we would expect there to be a substantial overlap between life cycle and labour market factors.

We measure labour market activity at the household level, the same unit of analysis as for our income measure. In constructing measures of change in labour market activity at the household level, problems arise since the household is not a static concept; there is considerable year-on-year household formation and dissolution. An increase in the number of workers in the household, resulting from partnership formation, for example, is perhaps more appropriately described as a non-labour market than a labour market phenomenon. Thus, we avoid classifying such changes in the level of household labour market activity as labour market events. ${ }^{24}$ In addition to the wave one employment status of the household, ${ }^{25}$ we include three dummy variables that capture changes in household labour market activity over the period as a whole. Two of these identify whether there was a net increase or decrease in household

24 First, we record whether an individual has increased or decreased their labour market activity between successive waves. A zero value is assigned to the transitions of household members who were not living with a member of our balanced panel in the previous year. We then compute a wave-on-wave measure of net change in household labour market activity by aggregating the changes in the labour market activity of each household member. Finally, we sum these changes for each individual over the ten waves to derive our measure of ten-year changes in household labour market activity.

25 The categories we use are the same as in Table 3. 
labour market activity over the ten years. ${ }^{26}$ The third dummy variable captures the amount of (in)stability and is equal to one if the individual experiences four or more changes in the labour market activity of the household(s) to which it belongs.

In Table 10, we report results for the probability of experiencing a given income trajectory as a function of (i) life cycle factors, (ii) labour market factors and (iii) both life cycle and labour market factors. The final column shows results from a multi-nominal logit regression for all income trajectories. The chi squared statistics indicate that the influence of life cycle factors is highly significant in all specifications i.e. whether included separately or alongside the labour market events.

Table 10: Relative Importance of Demographic and Labour Market Factors in Explaining Ten-Wave Income Trajectories

\begin{tabular}{ccccccc}
\hline \hline & Flat & $\begin{array}{c}\text { Flat with } \\
\text { blip(s) }\end{array}$ & Rising & Falling & Fluct. & All \\
\hline Life cycle factors: & & & & & & \\
chi2 & $243.9^{*}$ & $78.6^{*}$ & $349.0^{*}$ & $361.0^{*}$ & $113.1^{*}$ & $\mathbf{9 7 0 . 9 *}$ \\
$\quad \begin{array}{c}\text { Adjusted R } \\
\text { squared }\end{array}$ & 0.052 & 0.0139 & 0.116 & 0.0865 & 0.0279 & $\mathbf{0 . 0 6 4 4}$ \\
& & & & & &
\end{tabular}

\section{Labour market factors:}

$\begin{array}{lcccccc}\text { chi2 } & 387.9^{*} & 41.9^{*} & 412.7^{*} & 401.8^{*} & 274.1^{*} & \mathbf{1 3 0 7 . 8}^{*} \\ \begin{array}{l}\text { Adjusted R } \\ \text { squared }\end{array} & 0.0754 & 0.007 & 0.114 & 0.103 & 0.0701 & \mathbf{0 . 0 7 8 6}\end{array}$

\section{Combined:}

$\begin{array}{llcccccc}\text { Life cycle } & \text { chi2 } & 126.4^{*} & 68.3^{*} & 176.8^{*} & 139.7^{*} & 108.9^{*} & \mathbf{5 6 4 . 5 *} \\ \text { Labour market } & \text { chi2 } & 265.1^{*} & 29.9^{*} & 176.4^{*} & 208.7^{*} & 267.2^{*} & \mathbf{8 4 5 . 5}^{*} \\ & \text { Adjusted R } & 0.102 & 0.0192 & 0.162 & 0.139 & 0.0976 & \mathbf{0 . 1 1 4} \\ & \text { squared } & & & & & & \end{array}$

* Prob > chi2 equals 0.000

26 The reference category is no change in labour market activity. Net changes of plus or minus a half (e.g. a rise in labour market activity from no work to a part-time job), are counted as a change in net household labour market activity. 
The adjusted R-squared statistics in the separate models indicate that life cycle factors account for around four-fifths as much of the overall variation in income trajectories as is accounted for by labour market events (the figures are 0.0644 and 0.0786 respectively). When both sets of regressors are included in the same equation, life cycle factors are as good or nearly as good at explaining rising and falling trajectories. These observations are consistent with previous research which finds that demographic factors are important, but not as important as labour market factors, in explaining income risk (deviations from future expected income streams) and transitions into and out of poverty (Burgess et al, 2000; Jenkins and Rigg, 2001). Moreover, Burgess et al (2001) find that demographic events are more important for young individuals and high-income individuals - groups that are over-represented in the rising and falling trajectories (see Tables 2 and 3). ${ }^{27}$ Our results extend previous work in this area by classifying the type of income risk, rather than focusing solely on variations from the expected mean.

The evidence in Table 10 also points to substantial overlap between life cycle and labour market factors: the explanatory power of the multi-nomial logit containing both sets of regressors is less than the sum for the separate regressions. Nonetheless, both sets of factors also have an independent effect. This suggests that life cycle factors do not only operate through their impact on households' labour market activity.

In summary, life cycle factors do not explain as much of the variation in income trajectories as labour market factors. However, they have an important explanatory role, particularly in the case of rising and falling trajectories.

\section{Summary}

This paper has argued that our understanding of income and poverty dynamics can benefit from taking a life cycle perspective. The stage people are at in their lives affects their likelihood of experiencing particular life cycle events, such as partnership formation or having children, which in turn makes them more likely to experience rising, falling, or other income trajectories.

Using ten waves of the British Household Panel Survey, we show that during different life stages individuals have a substantially higher probability of

27

In separate results (not reported) for the sub-samples of individuals who are "ever poor" or "ever rich", we find that life cycle factors are relatively more important in explaining the variation in income trajectories for the "ever rich" than the "ever poor". 
experiencing particular income trajectories. Children, young single adults, single parents, and adults in couples with older children are more likely to be upwardly mobile, younger and older couples without children are more likely to be downwardly mobile, and pensioners are more likely to have relatively flat income trajectories.

The most important life cycle events associated with rising income trajectories are partnership formation and children becoming independent; around $20 \%$ of the population experience one of these events, but $40 \%$ of those with rising trajectories experience one of these events. In the case of falling trajectories, the most important events are having children and retirement, which are experienced by around $30 \%$ of the population but by $55 \%$ of those with falling trajectories.

From a policy perspective, income trajectories are of particular concern if they involve experiences of poverty. Our analysis shows that whilst having children is associated with a higher-than-average proportion of falling trajectories, most individuals who experience this event are relatively well off to start with and do not end up in poverty. On the other hand, those who are affected by partnership breakdown and who experience a falling trajectory are much more likely to fall into poverty. Those who experience the onset of disability are also more likelythan-average to experience a problematic income trajectory, at least in part because many of these individuals are disadvantaged to start with.

There is a large amount of heterogeneity in individuals' income trajectories following these different life cycle events. Typically, those who are affected by a particular event are around twice as likely to experience a particular income trajectory - for example, a rising trajectory in the case of partnership formation or a falling trajectory in the case of retirement. Still, most individuals will not follow the income trajectory most commonly associated with that life cycle event. In general, those who are relatively well off to start with are most adversely affected by 'negative' events, because they have more to lose. Gender differences also account for some of this variation - women, for example, benefit most financially from partnership formation, but appear to be worse affected by partnership breakdown.

The impact of life cycle factors on individuals' income trajectories over ten waves is highly significant. Although they have less overall explanatory power than labour market factors, they are almost as important in accounting for rising and falling income trajectories. 


\section{References}

Bardasi, E., Jenkins, S. and Rigg, J. (2001), 'Documentation for derived current and annual net household income variables, BHPS Waves 1-9', unpublished paper, Colchester: Institute for Social and Economic Research, University of Essex.

Bardasi, E., Jenkins, S. and Rigg, J. (2002), 'Retirement and the income of older people: a British perspective', Ageing and Society, 22, pp.131-159

Burgess, S., Gardiner, K., Jenkins, S., and Propper, C. (2000), Measuring Income Risk, CASEpaper 40, London: STICERD, London School of Economics.

Burgess, S., Gardiner, K., and Propper, C. (2001), Growing Up: School, family, and area influences on adolescent's later life chances, CASE Paper 49, London: STICERD, London School of Economics.

Department for Work and Pensions (2002), Households Below Average Income 1994/5-2000/01, Leeds: Corporate Document Service.

Falkingham, J. and Hills, J. (eds.) (1995), The Dynamic of Welfare: The Welfare State and the Life Cycle, Hemel Hempstead: Prentice Hall/ Harvester Wheatsheaf.

Gardiner, K, and Hills, J. (1999), 'Policy Implications of New Data on Income Mobility', The Economic Journal, 109, F91-F111

Glennerster, H. (1995), 'The Life Cycle: Public or Private Concern', ch. 2 from Falkingham, J. and Hills, J. (eds.) (1995), The Dynamic of Welfare: The Welfare State and the Life Cycle, Hemel Hempstead: Prentice Hall/ Harvester Wheatsheaf.

Jarvis, S. and Jenkins, S. (1997), 'Low Income Dynamics in 1990s Britain', Fiscal Studies, vol. 18, no. 2, pp.123-142.

Jarvis, S. and Jenkins, S. (1999), 'Marital splits and income changes: Evidence from the British Household Panel Survey', Population Studies, 53, pp.237-254.

Jenkins, S. and Rigg, J. (2001), The Dynamics of Poverty in Britain, Department for Work and Pensions Research Report No. 157, Leeds: Corporate Document Services.

Jenkins, S. and Rigg, J. (2003), Disability and disadvantage: selection, onset, and duration effects, Working Papers of the Institute for Social and Economic Research, paper 2004-18. Colchester: University of Essex. 
Rake, K. (ed.) (2000), Women's Incomes over the Lifetime, A report to the Women's Unit, Cabinet Office, London: The Stationery Office.

Stewart, M. (1999), 'Low Pay, No Pay Dynamics', in Persistent Poverty and Lifetime Inequality, H M Treasury Occasional Paper No.10.

Zaidi, A. (2001), Snakes and Ladders: An analysis if Life-Course Events and Income Mobility in Old Age, SAGE Discussion Paper 8, London: London School of Economics. 


\section{Appendix Tables}

Table A1: Relationship between trajectories in waves 1-4 and waves 1-10

\begin{tabular}{lccccc}
\hline $\begin{array}{l}\text { \% of individuals } \\
\text { Trajectories } \\
\text { over waves 1-4: }\end{array}$ & Flat & $\begin{array}{c}\text { Flat with } \\
\text { blip(s) }\end{array}$ & Rising & Falling & $\begin{array}{c}\text { Other } \\
\text { (incl. fluctuating) }\end{array}$ \\
\hline Flat & $\mathbf{4 4 . 1}$ & 20.5 & 11.9 & 16.2 & 7.3 \\
Blip & 11.8 & $\mathbf{3 7 . 7}$ & 13.7 & 12.8 & 24.0 \\
Rising & 10.4 & 24.7 & $\mathbf{2 4 . 3}$ & 3.5 & 37.1 \\
Falling & 7.7 & 26.0 & 5.1 & $\mathbf{2 2 . 4}$ & 38.8 \\
\hline Other & 2.8 & 19.9 & 11.6 & 10.9 & $\mathbf{5 4 . 9}$ \\
\hline All & & & & & \\
\hline \hline
\end{tabular}


Table A2: Probability of Experiencing Different Trajectory Types

Logistic regression estimates (odds ratios)

\begin{tabular}{|c|c|c|c|c|c|}
\hline & Flat & $\begin{array}{c}\text { Flat with } \\
\text { blip(s) }\end{array}$ & Rising & Falling & Fluct. \\
\hline Child & $\begin{array}{c}0.710 * * * \\
(2.83)\end{array}$ & $\begin{array}{l}0.930 \\
(0.67)\end{array}$ & $\begin{array}{c}1.625 * * * \\
(3.43)\end{array}$ & $\begin{array}{c}0.729 * * \\
(2.08)\end{array}$ & $\begin{array}{c}1.603 * * * \\
(2.93)\end{array}$ \\
\hline Young and single & $\begin{array}{c}0.590 * * * \\
(3.16)\end{array}$ & $\begin{array}{c}0.634 * * * \\
(2.76)\end{array}$ & $\begin{array}{c}2.435 * * * \\
(4.41)\end{array}$ & $\begin{array}{c}0.642 * * \\
(2.19)\end{array}$ & $\begin{array}{c}2.416 * * * \\
(4.10)\end{array}$ \\
\hline Single parent & $\begin{array}{c}0.429 * * \\
(2.56)\end{array}$ & $\begin{array}{l}0.736 \\
(1.12)\end{array}$ & $\begin{array}{l}1.723 * \\
(1.87)\end{array}$ & $\begin{array}{l}1.053 \\
(0.13)\end{array}$ & $\begin{array}{c}2.493 * * * \\
(2.76)\end{array}$ \\
\hline Young couple, no children & $\begin{array}{l}0.770 \\
(1.63)\end{array}$ & $\begin{array}{c}0.641 * * * \\
(2.62)\end{array}$ & $\begin{array}{l}0.823 \\
(0.64)\end{array}$ & $\begin{array}{l}1.196 \\
(1.00)\end{array}$ & $\begin{array}{c}1.743 * * \\
(2.31)\end{array}$ \\
\hline Couple with older children & $\begin{array}{l}0.823 \\
(1.39)\end{array}$ & $\begin{array}{c}0.768 * * \\
(1.98)\end{array}$ & $\begin{array}{c}2.730 * * * \\
(6.29)\end{array}$ & $\begin{array}{c}0.356 * * * \\
(5.05)\end{array}$ & $\begin{array}{c}2.040 * * * \\
(3.92)\end{array}$ \\
\hline Older couple, no children & $\begin{array}{c}0.625 * * * \\
(3.54)\end{array}$ & $\begin{array}{c}0.781 * * \\
(2.01)\end{array}$ & $\begin{array}{c}0.375 * * * \\
(4.22)\end{array}$ & $\begin{array}{c}1.519 * * * \\
(2.88)\end{array}$ & $\begin{array}{c}2.102 * * * \\
(4.36)\end{array}$ \\
\hline Older and single & $\begin{array}{l}0.879 \\
(0.68)\end{array}$ & $\begin{array}{l}0.923 \\
(0.44)\end{array}$ & $\begin{array}{c}0.619 * \\
(1.67)\end{array}$ & $\begin{array}{l}0.838 \\
(0.74)\end{array}$ & $\begin{array}{c}2.495 * * * \\
(3.87)\end{array}$ \\
\hline Pensioner couple & $\begin{array}{c}2.332 * * * \\
(5.43)\end{array}$ & $\begin{array}{c}0.736 * \\
(1.92)\end{array}$ & $\begin{array}{c}0.269 * * * \\
(3.99)\end{array}$ & $\begin{array}{l}1.334 \\
(1.42)\end{array}$ & $\begin{array}{l}0.716 \\
(1.30)\end{array}$ \\
\hline Single pensioner & $\begin{array}{c}1.583 * * * \\
(2.79)\end{array}$ & $\begin{array}{l}0.936 \\
(0.41)\end{array}$ & $\begin{array}{c}0.421 * * * \\
(3.05)\end{array}$ & $\begin{array}{l}1.060 \\
(0.25)\end{array}$ & $\begin{array}{l}0.994 \\
(0.02)\end{array}$ \\
\hline No health problems & $\begin{array}{l}0.855 \\
(1.22)\end{array}$ & $\begin{array}{l}0.975 \\
(0.21)\end{array}$ & $\begin{array}{l}1.104 \\
(0.54)\end{array}$ & $\begin{array}{l}1.200 \\
(1.22)\end{array}$ & $\begin{array}{l}1.327 * \\
(1.92)\end{array}$ \\
\hline Female & $\begin{array}{l}1.089 \\
(1.23)\end{array}$ & $\begin{array}{l}0.960 \\
(0.61)\end{array}$ & $\begin{array}{l}0.874 \\
(1.49)\end{array}$ & $\begin{array}{l}1.084 \\
(0.97)\end{array}$ & $\begin{array}{l}1.034 \\
(0.38)\end{array}$ \\
\hline Self-employed & $\begin{array}{c}0.356 * * * \\
(6.65)\end{array}$ & $\begin{array}{c}0.589 * * * \\
(4.30)\end{array}$ & $\begin{array}{c}1.524 * * \\
(2.57)\end{array}$ & $\begin{array}{c}0.597 * * * \\
(3.17)\end{array}$ & $\begin{array}{c}2.576^{* * *} \\
(7.04)\end{array}$ \\
\hline Adults all in FT employment & $\begin{array}{c}1.401 * * * \\
(2.88)\end{array}$ & $\begin{array}{c}0.781 * * \\
(2.20)\end{array}$ & $\begin{array}{c}1.693 * * * \\
(3.06)\end{array}$ & $\begin{array}{l}0.932 \\
(0.54)\end{array}$ & $\begin{array}{c}0.551 * * * \\
(3.72)\end{array}$ \\
\hline One FT and one PT worker & $\begin{array}{l}1.194 \\
(1.49)\end{array}$ & $\begin{array}{c}0.752 * * * \\
(2.58)\end{array}$ & $\begin{array}{c}2.551 * * * \\
(6.38)\end{array}$ & $\begin{array}{l}0.944 \\
(0.42)\end{array}$ & $\begin{array}{c}0.583 * * * \\
(3.26)\end{array}$ \\
\hline PT employment only & $\begin{array}{c}0.624 * * * \\
(2.91)\end{array}$ & $\begin{array}{c}0.614 * * * \\
(3.21)\end{array}$ & $\begin{array}{l}1.039 \\
(0.18)\end{array}$ & $\begin{array}{l}1.199 \\
(1.01)\end{array}$ & $\begin{array}{c}1.941 * * * \\
(4.06)\end{array}$ \\
\hline Head/ spouse unemployed & $\begin{array}{l}0.976 \\
(0.13)\end{array}$ & $\begin{array}{l}0.773 \\
(1.50)\end{array}$ & $\begin{array}{l}1.064 \\
(0.30)\end{array}$ & $\begin{array}{c}1.868 * * \\
(2.15)\end{array}$ & $\begin{array}{c}1.533 * * \\
(2.15)\end{array}$ \\
\hline Other & $\begin{array}{l}0.850 \\
(0.83)\end{array}$ & $\begin{array}{l}0.880 \\
(0.75)\end{array}$ & $\begin{array}{c}1.740 * * * \\
(2.76)\end{array}$ & $\begin{array}{l}0.754 \\
(0.95)\end{array}$ & $\begin{array}{c}0.627 * * \\
(1.98)\end{array}$ \\
\hline
\end{tabular}


Table A2 continued:

\begin{tabular}{lccccc}
\hline Bottom quintile & $2.035 * * *$ & 1.085 & $2.191 * * *$ & $0.027 * * *$ & 0.822 \\
& $(5.30)$ & $(0.69)$ & $(5.33)$ & $(7.76)$ & $(1.37)$ \\
Second quintile & $1.440 * * *$ & 0.989 & $2.302 * * *$ & $0.351 * * *$ & $0.755^{* *}$ \\
& $(3.01)$ & $(0.10)$ & $(6.85)$ & $(6.62)$ & $(2.10)$ \\
Fourth quintile & $1.624 * * *$ & 1.167 & $0.391 * * *$ & $1.305 * *$ & $0.739 * *$ \\
& $(4.26)$ & $(1.57)$ & $(6.51)$ & $(2.33)$ & $(2.38)$ \\
Top quintile & $3.635 * * *$ & $0.830 *$ & $0.080 * * *$ & $1.868 * * *$ & $0.456 * * *$ \\
& $(11.27)$ & $(1.69)$ & $(9.30)$ & $(5.33)$ & $(5.36)$ \\
\hline Adjusted R2 & 0.070 & 0.012 & 0.187 & 0.125 & 0.067 \\
Observations & 5306 & 5306 & 5306 & 5306 & 5306 \\
\hline \hline
\end{tabular}

Source: Own analysis using first ten waves of BHPS.

Absolute value of $\mathrm{z}$ statistics in parentheses

* significant at $10 \%$; ** significant at $5 \%$; *** significant at $1 \%$ 


\section{Table A3: Four Wave Income Trajectories for People Experiencing Different Events}

\begin{tabular}{|c|c|c|c|c|c|c|c|}
\hline \% of cases & Sample & Flat & $\begin{array}{l}\text { Blip } \\
\text { up }\end{array}$ & $\begin{array}{c}\text { Blip } \\
\text { down }\end{array}$ & $\begin{array}{l}\text { Rising } \\
\end{array}$ & Falling & Other \\
\hline All persons & 56,167 & 46.1 & 6.1 & 6.4 & 9.1 & 8.4 & 23.9 \\
\hline Left family home & 454 & 20.3 & 4.6 & 8.8 & 11.2 & 13.2 & 41.9 \\
\hline Formed partnership & 1,069 & 27.6 & 6.5 & 5.7 & 19.8 & 7.6 & 32.7 \\
\hline Split up & 826 & 23.4 & 6.4 & 6.8 & 9.3 & 17.6 & 36.6 \\
\hline Had child & 1,022 & 33.4 & 4.0 & 11.1 & 3.5 & 21.5 & 26.5 \\
\hline Children independent & 729 & 38.7 & 5.3 & 5.1 & 17.1 & 5.6 & 28.1 \\
\hline Disability (2+ waves) & 2,078 & 39.9 & 8.4 & 6.1 & 9.1 & 10.7 & 25.7 \\
\hline Retired & 1,529 & 37.1 & 4.8 & 9.9 & 6.0 & 17.0 & 25.1 \\
\hline Widowed & 205 & 39.5 & 5.4 & 8.8 & 8.8 & 12.7 & 24.9 \\
\hline None of above & 48,866 & 47.8 & 6.1 & 6.2 & 9.0 & 7.7 & 23.2 \\
\hline \multicolumn{8}{|l|}{ Interaction effects: } \\
\hline Left home to live with partner & 220 & 22.3 & 5.0 & 5.9 & 15.5 & 11.4 & 40.0 \\
\hline Left home - single person & 234 & 18.4 & 4.3 & 11.5 & 7.3 & 15.0 & 43.6 \\
\hline Partnership - lone mums + children & 396 & 22.2 & 11.9 & 5.6 & 23.5 & 4.0 & 32.8 \\
\hline Partnership - single women & 436 & 23.0 & 5.2 & 4.9 & 23.2 & 6.3 & 37.3 \\
\hline Partnership - men & 373 & 35.1 & 4.3 & 6.4 & 13.7 & 11.0 & 29.5 \\
\hline Split up - women \& children & 487 & 20.7 & 7.6 & 7.2 & 6.0 & 23.2 & 35.3 \\
\hline Split up - women no children & 100 & 20.0 & 5.0 & 9.0 & 13.0 & 18.0 & 35.0 \\
\hline Split up - men no children & 97 & 34.0 & 3.1 & 7.2 & 9.3 & 8.2 & 38.1 \\
\hline Split up - men with children & 84 & 15.5 & 7.1 & 1.2 & 28.6 & $\mathbf{0 . 0}$ & 47.6 \\
\hline Children independent - left home & 117 & 35.0 & 7.7 & 4.3 & 22.2 & 10.3 & 20.5 \\
\hline Children independent - at home & 612 & 39.4 & 4.9 & 5.2 & 16.2 & 4.7 & 29.6 \\
\hline Disability - retired & 481 & 50.9 & 10.6 & 4.4 & 5.0 & 9.8 & 19.3 \\
\hline Disability - prev. working & 859 & 34.6 & 6.1 & 8.6 & 8.7 & 12.1 & 29.9 \\
\hline Disability - prev. not working & 754 & 39.4 & 9.4 & 4.5 & 12.2 & 9.8 & 24.7 \\
\hline Retired - prev. working & 604 & 22.7 & 2.3 & 15.2 & 3.0 & 27.2 & 29.6 \\
\hline Retired - prev. not working & 952 & 46.0 & 6.3 & 6.5 & 7.9 & 11.1 & 22.2 \\
\hline Widowed - non-pens. & 68 & 32.4 & 4.4 & 7.4 & 7.4 & 23.5 & 25.0 \\
\hline Widowed - older women & 95 & 45.3 & 5.3 & 10.5 & 6.3 & 7.4 & 25.3 \\
\hline Widowed - older men & 42 & 38.1 & 7.1 & 7.1 & 16.7 & 7.1 & 23.8 \\
\hline
\end{tabular}

Source: Own analysis using first ten waves of BHPS.

Lightly shaded boxes indicate substantially lower-than-average probabilities (at least 1.5 times lower than average). Darkly shaded boxes indicate substantially higher-than-average probabilities (at least 1.5 times higher than average). 